\title{
The genus Microplinthus, with description of four new species (Coleoptera: Curculionidae: Molytinae)
}

\author{
MASSIMo MEREGALLI \\ Dip. di Biologia Animale e dell'Uomo, Università di Torino, V. Accademia Albertina 13, I-10123 Torino, Italy; \\ e-mail: massimo.meregalli@unito.it
}

Key words. Taxonomy, new species, Coleoptera, Curculionidae, Molytinae, Microplinthus, Himalaya

\begin{abstract}
The genus Microplinthus Zherikhin, 1987 is revised. It is assigned to the tribe Aminyopini Voss, 1956, based on the female genitalia and the presence of appendiculate claws in one species. The following new species are described: M. parbatensis sp. n. (Central Nepal); M. kaligandaki sp. n. (Central Nepal); M. shiva sp. n. (India: Darjeeling); M. laurae sp. n. (India: Darjeeling; Sikkim; Central-western Nepal?). The genus is apparently the sister group to Falsanchonus Zherikhin, 1987. Mutual relationships among the nine species of Microplinthus are suggested based on a phylogenetic analysis.
\end{abstract}

\section{INTRODUCTION}

The rich material of Curculionoidea recently collected in the Himalaya region is the basis for a series of studies on the systematics of the oriental fauna of the subfamily Molytinae. Two works were recently published on two genera belonging to this subfamily (Meregalli, 2003a, b) and this new contribution is concerned with the genus Microplinthus Zherikhin, 1987.

\section{MATERIAL AND METHODS}

This study is based on material housed in the following collections:

$\mathrm{BMNH}=$ The Natural History Museum, London, UK

$\mathrm{CMNC}=$ Canadian Museum of Nature, Ottawa, Canada

MER = Massimo Meregalli, Torino, Italy

NHMB = Naturhistorisches Museum, Basel, Switzerland

SMNS = Staatliches Museum für Naturkunde, Stuttgart, Germany

ZIN = Russian Academy of Sciences, Zoological Institute, St. Petersburg, Russia

All the specimens examined were dissected, the female genitalia were embedded in Canada balsam and male genitalia were mounted dry, with the internal sac of the aedeagus of some males dissected and embedded in Canada balsam. Preparations of the genitalia were pinned below the specimen from which they were dissected. The localities are sorted according to the country and reported between " " as written on the labels, with the year always indicated with four digits. The geographical position of the precisely localised collecting places, if not indicated on the label, is given between square brackets, together with the correct geographic name if the original spelling is not correct. The terminology mainly follows van den Berg (1972) and Aslam (1963). Phylogenetic analyses were conducted with unweighted characters using the Phylogeny Inference Package PHYLIP 3.6b (Felsenstein, 2004). The multistate matrix was converted into a binary matrix with the "Factor" program, with ancestral states considered when identified. The "Seqboot" programme was then used to produce 1000 bootstrapped data sets. Several parsimony programs were run on these data sets and the most parsimonious trees according to the Wagner and CaminSokal (cf. Felsenstein, 2004) methods were obtained; the majority-rule consensus tree was then derived with the "Consense" program.

\section{Microplinthus Zherikhin, 1987 \\ Microplinthus Zherikhin, 1987: 37.}

Type species. Microplinthus morimotoi Zherikhin, 1987 by original designation.

Re-description. Curculionidae: Molytinae: Aminyopini of small size $(2.8-5 \mathrm{~mm})$, wingless. Body slender, ovateelliptical to nearly cylindrical; integument with shallow microsculpture, usually moderately glossy, reddish to dark reddish-brown, antennae and tarsi dark red. Vestiture consisting of scattered setae, usually erect, sometimes recumbent, usually as long as or longer than the width of the intervals, rarely shorter, straight or curved at apex, from hair-like to $3 \times$ longer than wide and irregularly inserted in a single row on intervals; setae usually more frequent on the odd intervals and occasionally grouped or in tufts on the humps of elytra; scales, or short setae, are present on elytra, scarcely erect or completely appressed to integument, often scarce but in some species relatively frequent; legs with numerous setae, erect, curved or slightly recumbent at apex. Rostrum stout, approximately as long as the pronotum, curved at about $45^{\circ}$ with respect to the head, semicircular or flattened dorsally in transverse section; dorso-lateral margins usually not sharply delimited, subparallel or moderately converging forward; surface usually (except in $M$. minor) nearly matt from base to insertion of antennae, with dense round punctures more or less aligned in 5 rows separate by narrow, sometimes barely distinct glossy linear interspaces; apex usually reddish, glossy, smooth or minutely micro-punctulate; base of rostrum in lateral view often weakly sinuate with respect to head, dorsum regularly, sometimes moderately, curvilinear, not or barely thickened [moderately thickened only in M. minor (Zherikhin, 1987)], ventral side nearly straight; sides below scrobes (pregenae) distinctly broadened, with apical part of scrobes fully visible from above; maximum width of ros- 
trum at apex. Epistoma distinct, flat, slightly sinuate inward at middle. Scrobes glossy, narrow, oblique; upper margin quite sharply delimited, reaching the eye at middle of its anterior side; lower margin parallel to upper one, reaching the underside of rostrum near base. Prementum moderately narrowed basad, its minimum width at least as wide as the basal part of the scrobes. Antennae sub-apical; scape clavate, often abruptly thickened at apex, usually with some erect setae on anterior side near apex; funicle 7-segmented, segments 1-2 moderately elongate, 3-7 smaller, isodiametric or transverse; club ovate-elliptical, tomentose, 4-segmented, segment 1 shorter than 2-4 together, all sutures on club scarcely visible. Chaetotaxy: one seta at the apex of rostrum, lateral to epistoma; one seta at the apex of pregenae; one seta at the middle of mandible, basal, and one at the apex of labium. Head short, globose, punctured, moderately inserted into the pronotum; vertex broader than the base of rostrum; eyes lateral, ovate to elliptical, flat, small. Pronotum more or less isodiametric, weakly convex on dorsum, base nearly straight, sides subparallel, occasionally slightly constricted at apex; apical margin subtruncate, not or moderately protruded above the head, often slightly emarginate inward at middle; dorsum and sides with dense, often regularly impressed round punctures, large or small to very small; median line, if present, usually narrow, irregular. Sides sub-truncate or with scarcely developed post-ocular lobes. Scutellum not visible or minute. Elytra elongate; humeri not broadened; suture locked; base weakly arched, usually as large as or slightly larger than the base of pronotum; sides subparallel or moderately curved, with maximum width at middle of their length or near their base; dorsum flattened or weakly convex; declivity, in lateral view, regularly curving from dorsum, not sharply vertical. Striae 10, 1-9 complete from base to apex or at least to declivity, stria 10 very narrow, punctures small, barely visible, usually present from base to apex. Punctures in the striae round or subquadrate, usually dense and regularly aligned, wider than the intervals on dorsum, usually narrowed and shallower on declivity. Intervals nearly flat or, in some species, odd intervals weakly convex, smooth, sometimes with low elongate humps but lacking differentiated high granules or tubercles; interval 3 and 5 usually slightly higher at base, 5 interrupted at the beginning of the declivity but not or scarcely raised at this point. Prosternum deeply excised; excision limited to the anterior half; base above the coxae slightly swollen; intercoxal process acute, not developed. Mesosternum short, punctured, intercoxal process rounded apicad. Metasternum shorter than the width of the middle coxae, punctured. Fore coxae round, contiguous; middle coxae round, barely separate; hind coxae transverse, separate. Trochanters with one seta. Ventrites 1 and 2 fused, 1 as long as 2 , suture between 1 and 2 slightly deepened on the sides, scarcely distinct at middle; ventrite 2 longer than 3 and 4 together; these short, isomorphic; ventrite 5 as long as 3 and 4 together, semi-circular, apex with two groups of setae at posterior-lateral margin, each group consisting of 2-3 setae, one of which often longer. Ventrites 1, 2 and 5 punctured, 3 and 4 nearly smooth; intercoxal process of ventrite 1 broad, subtruncate. Femora densely punctured or wrinkled, weakly or moderately clavate, with a small or barely distinct tooth on the middle of the inner side. Tibiae short, straight; fore tibiae with oblique or slightly sinuate apical fringe of setae; subapical fringe absent. Middle and hind tibiae with ascending, sinuate fringe. Tarsi short, segment 1 conical, 2 isodiametric, 3 bilobed, lobes scarcely developed; underside with incomplete whitish pilose pads and usually long marginal setae; onychium slender; claws free, narrow, widely divergent, usually not appendiculate or with a small inner tooth (Fig. 37). Aedeagus from weakly to strongly curved, convex side membranous, apex simple, rounded-ogival or elongate, acutely tapering; endophallus minutely denticulate, lacking large sclerites; tegmen oval, with narrow strut and relatively well developed parameroid lobes. Hemisternites cylindrical, styli slender; sternum VIII of female subquadrate or slightly elongate, arms fused at half of its length, with narrow and slender strut only bifurcate at the base or simply joined towards the base and bifurcated from the junction point (Figs 30-35). Blades of proventriculus rectangular, with setae distributed as in Fig. 29.

\section{KEY TO THE SPECIES}

1 Claws with small, clearly visible inner tooth (Fig. 37). Length 4.1-4.3 mm. Central Nepal. . . M. parbatensis sp. $\mathrm{n}$.

- Claws simple....................... 2

2 Basal half of rostrum glossy red, thickened in lateral view (Fig. 42), with small and shallow punctures. Length $3 \mathrm{~mm}$. Eastern Nepal. . . . . . . . . M. minor (Zherikhin, 1987)

- Basal half of rostrum dark brown or blackish, matt, not or barely thickened in lateral view, with dense punctures and usually longitudinal lines. . . . . . . . . . . . . 3

3 Odd intervals with distinct low humps, where tufts of setae are inserted. . . . . . . . . . . . . . . 4

- Odd intervals without humps; setae more or less regularly spaced, sometimes grouped but never in tufts. . . . . . 6

4 Elytra convex on dorsum (Fig. 48); rostrum thick, barely curved (Fig. 44). Length $4.35 \mathrm{~mm}$. Northern India: Darjeeling............................ shiva sp. $\mathrm{n}$.

- Elytra flattened on dorsum (Fig. 49); rostrum regularly curved...................... 5

5 Setae on odd intervals erect, as long as the interval width; rostrum wider at base than at insertion of antennae, dorsum regularly and weakly convex. Length $4.9-5.1 \mathrm{~mm}$. Eastern Nepal. . . . . . . . . . . . M. morimotoi Zherikhin, 1987

- Setae on odd intervals short, curved, shorter than the interval width; rostrum at base as wide as at insertion of antennae, base of rostrum narrowed, compressed laterally out of dorsal keels. Length $5 \mathrm{~mm}$. Eastern Nepal. ........ M. maior (Zherikhin, 1987)

6 Small; setae on elytra short, scarcely visible. Length 2.9 mm. Eastern Nepal. . . . . . . . M. minimus Zherikhin, 1987

- Larger; setae on elytra long, narrow or broader, erect. . . . 7

7 Sides of pronotum broadened towards apical third, constricted at apex (Fig. 62); setae on elytra erect, narrow, very long, regularly spaced. Length $4.2 \mathrm{~mm}$. Central Nepal. . . . . M. setulosus Zherikhin, 1987 - Sides of pronotum subparallel, moderately converging at apex $($ Figs 61,68$) \ldots \ldots \ldots \ldots \ldots \ldots \ldots \ldots$ 
8 Broader; setae on elytra long, erect, regularly inserted, not grouped. Length $3.7 \mathrm{~mm}$. Central Nepal. . . . . . . . . . . . . .

M. kaligandaki sp. $\mathrm{n}$

- Narrower; setae on elytra very broad, more or less grouped. Length 3.8-4.2 mm. Northern India: Darjeeling; Sikkim; ? central Nepal. . . . . . . . . . . . . . . Marae sp. n.

\section{Microplinthus parbatensis sp. $\mathbf{n}$.}

Figs 1-2, 13, 26, 29, 33, 36, 37, 39, 51, 60, 69

Type locality. Nepal, Parbat District, Ghorapani Pass, $28^{\circ} 23^{\prime} \mathrm{N} 83^{\circ} 41^{\prime} \mathrm{E}$.

Diagnosis. A Microplinthus of medium size, integument dark reddish, rough, intervals with small minute glossy granules, claws with small inner tooth.

Measurements. Body length $4.14 \mathrm{~mm}$. Rostrum: length 1.19 $\mathrm{mm}$, width at base $0.41 \mathrm{~mm}$; width between antennae $0.35 \mathrm{~mm}$, width at apical plate $0.47 \mathrm{~mm}$. Pronotum: length $1.33 \mathrm{~mm}$, width $1.40 \mathrm{~mm}$ (length/width ratio 0.95). Elytra: length 2.72 $\mathrm{mm}$, width $1.92 \mathrm{~mm}$ (length/width ratio 1.41). Elytra/pronotum width ratio 1.37 (holotype).

Description. Body dark reddish to brown, integument scarcely glossy, rough, wrinkled. Vestiture: setae on the rostrum short, scarcely visible, appressed to the integument; setae on the pronotum short, inserted at the margin of the punctures and usually completely lying into the punctures; setae on the elytra as long as the intervals, moderately erect but not perpendicular to the surface, more or less uniseriate and regularly spaced on the odd intervals, more frequent on the declivity; sub-rectangular scales scattered on the whole surface, irregularly aligned in 3-4 rows on the intervals, relatively dense, interspaces between them wider than their size; setae on the legs spaced, erect. Rostrum shorter than the pronotum, broader at the base, slightly narrowed towards the insertion of the antennae, evenly curved from the vertex in lateral view; dorsum very densely punctured from the base to the insertion of the antennae; punctures small, round, deeply impressed, not regularly aligned, sometimes fused, lacking longitudinal keels or glossy lines; apex glossy, unpunctured; pregenae glossy, with spaced punctures. Upper margin of the scrobes keeled, lower margin smooth, extended beyond the antenna towards the apex. Antennae slender; scape regularly thickened at the apex; segments 1 and 2 of the funicle longer than wide, of equal length, 3-7 subquadrate, club oval. Vertex as strongly punctured as the base of the rostrum; eyes oval. Pronotum nearly isodiametric, base truncate; sides subparallel from the base to the apical third, obliquely converging apicad; dorsum with very dense round punctures, margins of the punctures raised, narrow; median line small, short, barely distinct; sides densely punctured. Elytra ovate-elliptical; base moderately arched, slightly wider than the base of the pronotum, sides very weakly broadened from the base, evenly converging apicad; intervals as wide as the striae, wrinkled; odd intervals slightly more convex, mainly on the declivity, with a series of small glossy granules in which the erect setae are inserted; striae with round seriate punctures, regularly aligned and separated by a minute glossy granule. Femora scarcely thickened at middle, untoothed; tibiae slender, rectilinear, apex with rounded fringe of setae, not strongly ascending; tarsi short, segment 3 scarcely broadened, onychium thick, claws with minute, but clearly distinct, inner tooth. Ventrites 1, 2 and 5 densely punctured. Aedeagus: Figs 1-2, 13. Sternum VIII of female: Fig. 33.

Type material. Holotype 0 : NEPAL: "Nepal, Parbat Distr., Ghoropani Pass, N slope, 2700 m, 6.X.1983, Smetana \& Löbl legg., M. \& A. Howden coll." [= Ghorapani Pass, $28^{\circ} 23^{\prime} \mathrm{N}$ $\left.83^{\circ} 41^{\prime} \mathrm{E}\right]$ (CMNC). Paratypes: same data, $3 q$ (2ㅇ CMNC, 19 MER).

Variation. The three paratypes do not show any particular variation with respect to the holotype, only pronotum can be slightly longer.

Etymology. Named after the type locality, the Parbat District in central Nepal.

Distribution. Only known from the single original collection site (Fig. 79).

Remarks. This species is easily differentiated from all the other Microplinthus by the presence of glossy granules on the intervals, the small and dense punctures on the pronotum, the frequent scales on the elytra and, above all, the small inner teeth on the claws. It has a general morphological resemblance to the monotypic genus Microniphades Zherikhin, 1987, in particular for the body form and colour, the slender antennae, and the elytral sculpture.

\section{Microplinthus kaligandaki sp. $\mathbf{n}$.}

Figs 5-6, 15, 23, 40, 50, 52, 61, 70

Type locality. Nepal, Sikha, $28^{\circ} 26^{\prime} \mathrm{N} 83^{\circ} 40^{\prime} \mathrm{E}$.

Diagnosis. A Microplinthus of medium size, characterised by the short, scarcely curved rostrum, not thickened in lateral view, the elytral intervals lacking humps, with setae regularly placed, not grouped, perpendicularly inserted, and the aedeagus with round apex.

Measurements. Body length $3.70 \mathrm{~mm}$. Rostrum: length 0.91 $\mathrm{mm}$, width at base $0.33 \mathrm{~mm}$; width between antennae $0.30 \mathrm{~mm}$, width at apical plate $0.37 \mathrm{~mm}$. Pronotum: length $1.19 \mathrm{~mm}$, width $1.07 \mathrm{~mm}$ (length/width ratio 1.11). Elytra: length 2.36 $\mathrm{mm}$, width $\mathrm{mm} 1.53$ (length/width ratio 1.54). Elytra/pronotum width ratio 1.42 (holotype).

Description. Body oblong, integument dark brownishred, moderately glossy, tarsi dark red, antennae orange. Vestiture: setae on the rostrum frequent, wide, inserted on the outer side of punctures and directed towards the centre, appressed above integument; sparse setae on the pronotum moderately erect, more frequent on the sides; setae on the elytra sub-perpendicularly inserted on the intervals, regularly spaced, never grouped, more spaced and scarce on the dorsum, quite frequent on the sides and the declivity, as long or slightly longer than the interval width; scales rectangular, sparse, recumbent. Rostrum distinctly shorter than pronotum, weakly curved in lateral view with respect to the head, not thickened, curvature of dorsum very regular, continuous with vertex curvature. Dorsum deeply punctured; punctures round, wide, aligned in four rows separated by narrow irregular longitudinal lines; apex glossy, indistinctly punctured; pregenae with two basal rows of punctures individually impressed and parallel to the lower margin of the scrobe. Sides above the 

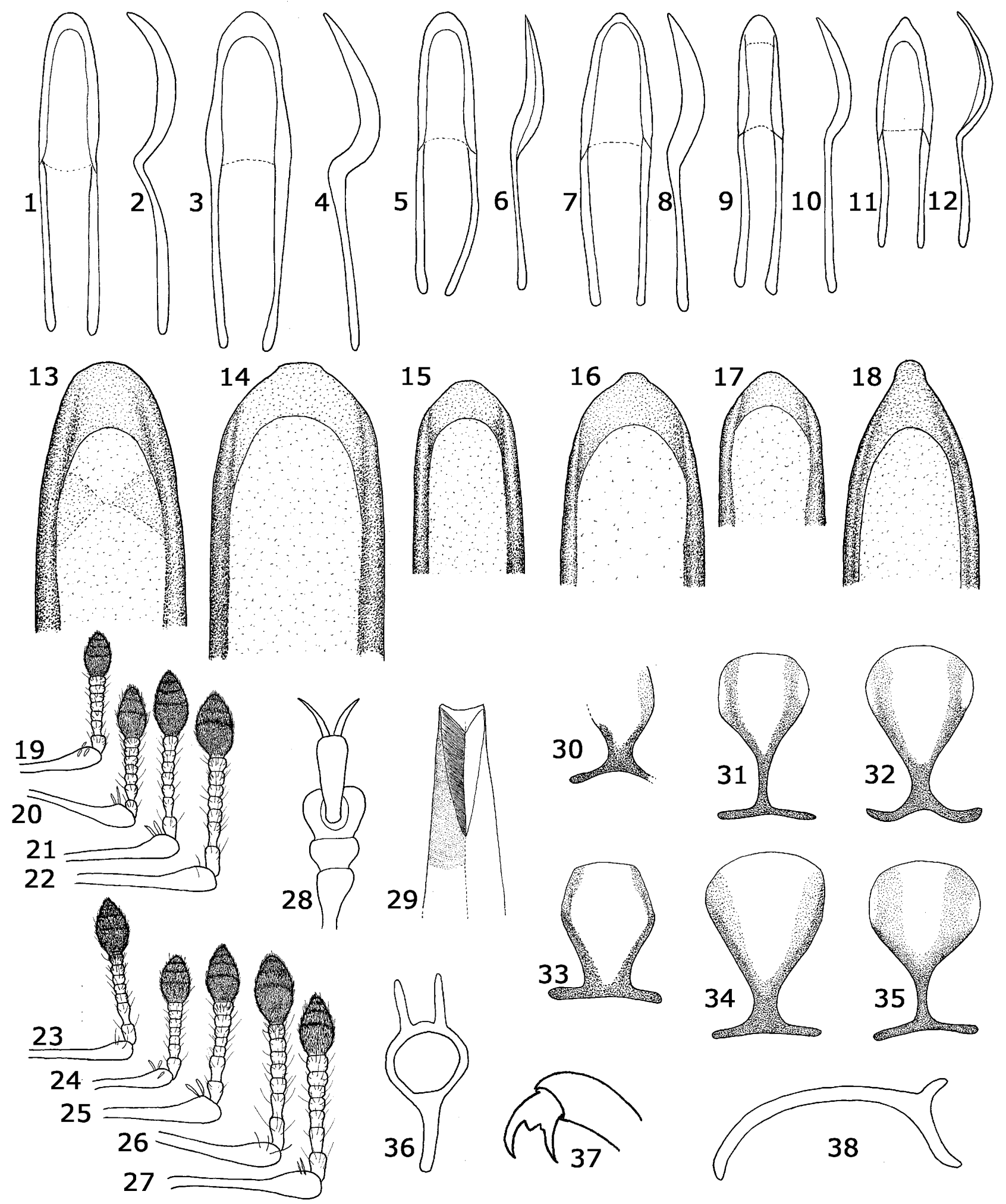

Figs 1-38. Aedeagus: dorsum, profile and detail of apex of: M. parbatensis, holotype (1-2, 13); M. morimotoi, holotype (3-4, 14); M. kaligandaki, holotype (5-6, 15); M. laurae, holotype (7-8, 16); M. minor, holotype (9-10, 17); M. minimus, holotype (11-12, 18). Antenna of: M. minimus, holotype (19); M. laurae, holotype (20); M. setulosus, holotype (21); M. maior, holotype (22); M. kaligandaki, holotype (23); M. minor, holotype (24); M. shiva, holotype (25); M. parbatensis, holotype (26); M. morimotoi, holotype (27). Fore tarsus of: M. setulosus, holotype (28). Blade of proventriculus of M. parbatensis, paratype (29). Sternite VIII of : M. setulosus, holotype (30); M. laurae, paratype, Budubara (31); M. cf. laurae, Sikkim (32); M. parbatensis, paratype (33); M. morimotoi, Tseram (34); M. maior, holotype (35). Tegmen of M. parbatensis, holotype (36). Claws of M. parbatensis, holotype (37). Spiculum gastrale of M. morimotoi, Tseram (38). Bar: Figs 1-12, 19-28, 30-36: 1 mm; Fig. 37: 0.5 mm; Figs 13-18, 29, $38: 0.33$ mm 
scrobes with 2-3 rows of punctures at the base, reduced to a single row towards mid length. Scrobes narrow, upper and lower margins parallel. Scape of antenna moderately thickened at the apex, with few narrow apical setae. Segment 1 of the funicle globose, $1.5 \times$ longer than wide; segment 2 conical, as long as 1; segments 3-7 transverse. Club oblong. Vertex with deep reticulate punctures, barely smaller than those in the base of the rostrum; eyes ovate, flat. Pronotum isodiametric; base truncate, sides barely and linearly broadened from base to apical third, weakly compressed to apex; apex subtruncate, indistinctly emarginate at middle; post ocular and dorsal lobes moderately developed. Dorsum with dense and deep round punctures, often grouped and converging into short rows; interspaces narrow and indistinctly delimited; central line distinct in the apical half. Punctures on the sides dense, reticulate. Elytra elliptical; sides subparallel, regularly converging apicad. Intervals linear, narrow, lacking humps; odd intervals slightly wider and more convex than the even; interval 5 scarcely raised on the declivity; striae wider than the intervals, particularly on the dorsum, with round seriate punctures; interspaces between the punctures with a minute granule, more distinct on the basal half of striae 1 and 2. Legs short, femora with a small inner tooth; tibiae straight, not widened apicad, with erect setae; surface with dense and large oblong wrinkles, apical fringe of setae of fore tibiae oblique, fully ascending; tarsi short, segment 1 triangular, 2 transverse, 3 subquadrate, weakly bilobed; claws simple. Ventrites 1 and 2 with round punctures; interspaces black, matt, microsculptured, as large as the punctures; 3-5 glossier, dark reddish, 5 with shallow punctures. Aedeagus: Figs 5-6, 15.

Type material. Holotype ô: NEPAL: "Nepal, Sikha, $83^{\circ} 40^{\prime} \mathrm{E}$ $28^{\circ} 26^{\prime} \mathrm{N}, 8000 \mathrm{ft} ., 24-26 . V .1954$, K.H. Hyatt, litter of oak forest, B.M., Nepal Expdt., BM 1954-540” (BMNH).

Etymology. Kaligandaki, a noun in apposition. The village of Sikha lies in the valley of the Kaligandaki, Nepal's most holy river, named after goddess Kali.

Distribution. Species known from the single original collection site (Fig. 79).

Remarks. $M$. kaligandaki is sympatric with $M$. parbatensis, differing from it by several traits, the most easily seen being the appendiculate claws. M. setulosus is apparently the most closely related species. It can be distinguished by the longer rostrum, slightly more thickened in lateral view (Figs 40, 45), the thicker setae at the apex of the scape, the sides of the pronotum distinctly broader, the longer setae on the elytra, the shorter and completely recumbent setae on the tibiae and the denser punctures on ventrites 1 and 2, with interspaces narrower than the punctures. The other species from central Nepal, M. mini$m u s$, is smaller and has an acute apex of aedeagus.

\section{Microplinthus setulosus Zherikhin, 1987}

Figs 21, 28, 30, 45, 53, 62, 71

Microplinthus setulosus Zherikhin, 1987: 40.

Measurements. Body length $4.18 \mathrm{~mm}$. Rostrum: length 1.19 $\mathrm{mm}$, width at base $0.40 \mathrm{~mm}$; width between antennae $0.29 \mathrm{~mm}$, width at apical plate $0.49 \mathrm{~mm}$. Pronotum: length $1.29 \mathrm{~mm}$, width $1.34 \mathrm{~mm}$ (length/width ratio 0.96). Elytra: length 2.70 $\mathrm{mm}$, width $1.82 \mathrm{~mm}$ (length/width ratio 1.48). Elytra/pronotum width ratio 1.35 (holotype).

Redescription. Body of medium size $(4.2 \mathrm{~mm})$, reddish dark, antennae and tarsi orange-red, integument moderately glossy. Vestiture: setae on the rostrum small, transversely inserted into the punctures, appressed to the integument; setae on the pronotum long, nearly but not completely appressed to the integument, slightly lifted on some parts of the surface, inserted into the punctures and usually longer than the puncture width; setae on the elytra erect, longer than the interval width, quite regularly spaced on the odd intervals, about 5-6 on the dorsum from base to the declivity, more frequent towards the apex; scales twice as long as wide, scattered on the whole surface, recumbent on the sides and nearly appressed to the integument on the dorsum; setae on the legs short, scarcely lifted. Rostrum nearly as long as the pronotum; moderately and regularly curved from the base to the apex and weakly sinuate beyond the vertex in lateral view; dorsum coarsely and irregularly punctured, regularly convex with barely distinct longitudinal lines; apex glossy, very minutely punctulate; pregenae densely punctured at base, smooth at apex. Upper margin of the scrobe slightly sinuate at middle, not keeled. Scape of antennae narrow, moderately thickened at apex; segment 1 of the funicle globose, 2 narrower than first, 3-7 subquadrate; club shortly ovate. Head globose, smooth, vertex as strongly punctured as the base of the rostrum; eyes flat. Pronotum slightly wider than long; base weakly arched, sides straight and divergent from base to apical third, curvilinearly constricted before apex; dorsum densely and coarsely punctured, punctures often converging in short rows, interspaces narrow, convex; median line small but distinct on the anterior half; sides more shallowly sculptured, with weakly delimited punctures. Base of elytra slightly wider than the base of the pronotum; sides weakly broadened in the basal quarter, subparallel for most of their length and regularly converging at apex. Odd intervals slightly more convex than even, with some broad and scarcely raised granules bearing the erect setae, 3 and 5 higher at base; even intervals narrower, flat; punctures of the striae dense, seriate, broader and deeper at the base and progressively smaller and shallower towards declivity and apex; interspaces between the punctures small, with a low trace of granule. Legs slender, femora scarcely thickened medially, with a small inner tooth; tibiae with longitudinal wrinkles; apical fringe of setae ascending; tarsi with segment 3 broader than 2; claws simple, with a basal thickening barely visible even at high enlargement. Ventrites 1 and 2 regularly punctured, punctures small, interspaces at least as wide as the punctures; 3-4 with shallow punctures, scarcely visible; 5 with small, dense and shallow punctures. Sternite VIII: Fig. 30.

Material examined. Holotype + : NEPAL: "Nepal, Gorkha Distr., Chuling Khola, Meme Kharka, 3300-3400 m, Abies- 

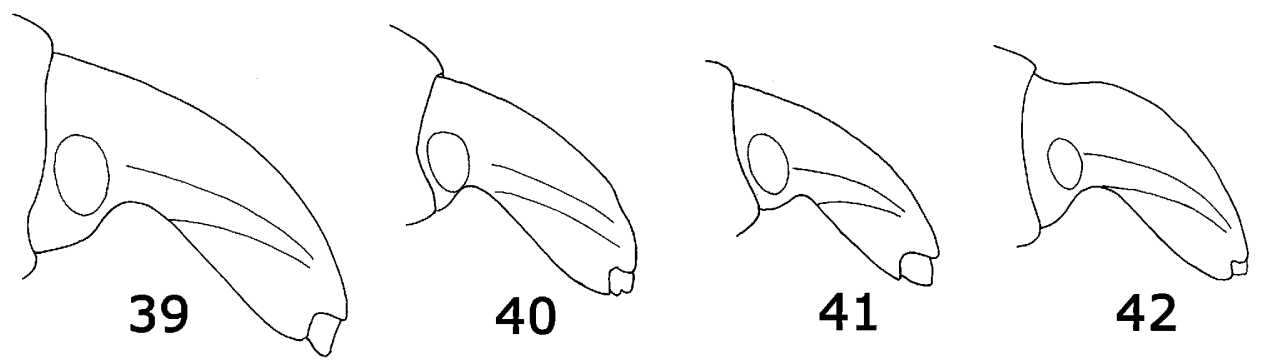

41

42
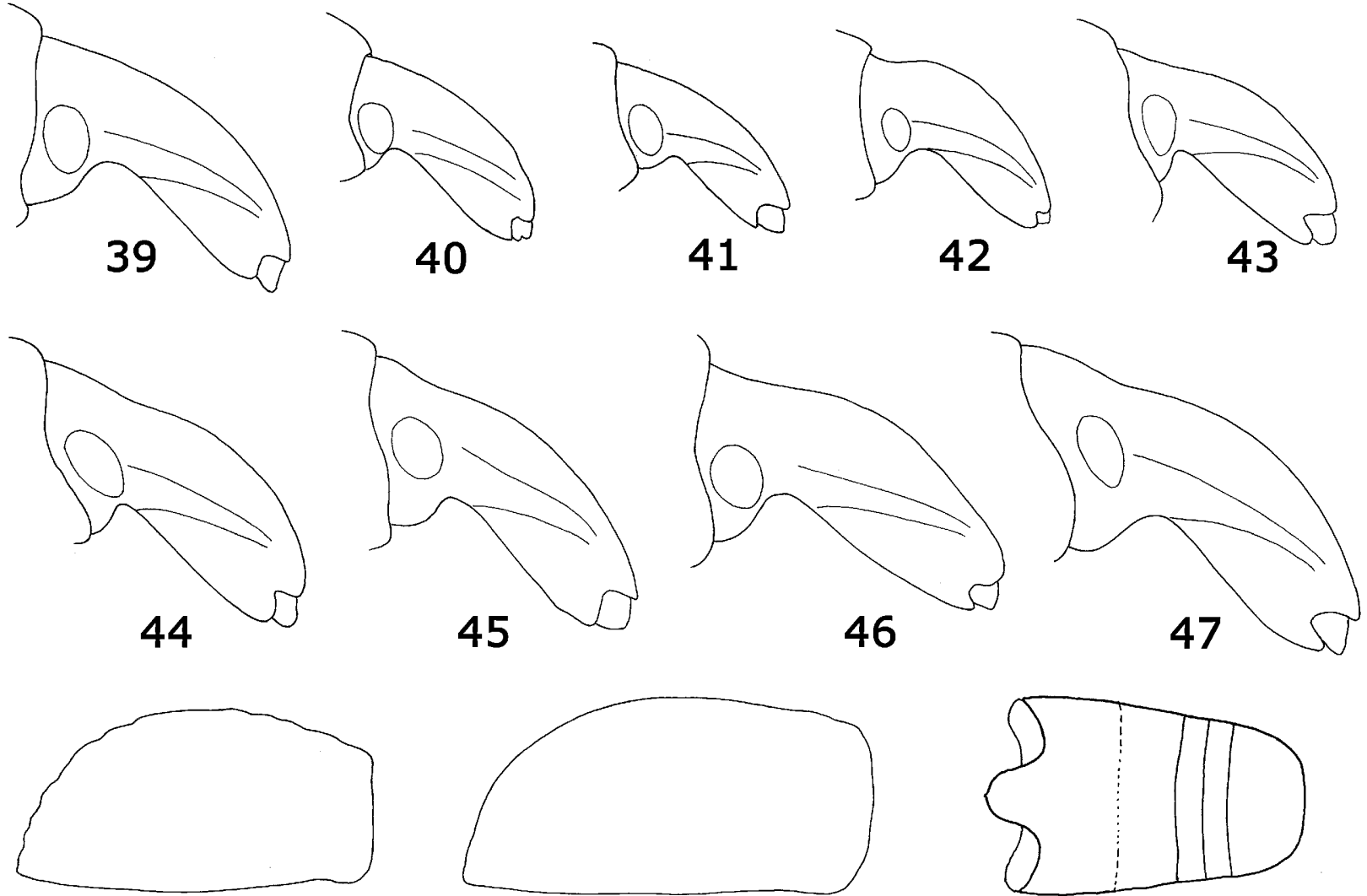

49

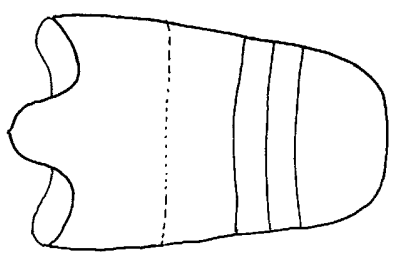

48

50

Figs 39-50. Rostrum, lateral view, of: M. parbatensis, holotype (39); M. kaligandaki, holotype (40); M. minimus, holotype (41); M. minor, holotype (42); M. laurae, holotype (43); M. shiva, holotype (44); M. setulosus, holotype (45); M. maior, holotype (46); M. morimotoi, holotype (47). Profile of elytra of: M. shiva, holotype (48); M. morimotoi, holotype (49). Ventrites of M. kaligandaki, holotype (50). Bar: Figs 39-47: $1.5 \mathrm{~mm}$; Figs 48-49: $3 \mathrm{~mm}$; Fig. 50: $2.5 \mathrm{~mm}$

Rhododendron forest, Berlese, 5-6.VIII.1983, leg. Martens \& Schawaller" [282 $\left.28^{\prime} \mathrm{N} 84^{\circ} 46^{\prime} \mathrm{E}\right]$ (SMNS).

Distribution. Known from a single specimen collected in central Nepal (Fig. 79).

Remarks. This species is characterised by the peculiar structure of the pronotum (Fig. 62), whose sides are distinctly widened from the base to the apical third. This trait allows an easy differentiation from the other species. Other discriminative characters are the elytra without humps and with very long setae, regularly spaced, never grouped.

\section{Microplinthus morimotoi Zherikhin, 1987}

Figs 3-4, 14, 27, 34, 38, 47, 49, 54, 63, 72

Microplinthus morimotoi Zherikhin, 1987: 38.

Measurements. Body length $4.90 \mathrm{~mm}$. Rostrum: length 1.28 $\mathrm{mm}$, width at base $0.49 \mathrm{~mm}$; width between antennae $0.39 \mathrm{~mm}$, width at apical plate $0.53 \mathrm{~mm}$. Pronotum: length $1.54 \mathrm{~mm}$, width $1.52 \mathrm{~mm}$ (length/width ratio 1.01). Elytra: length 3.34 $\mathrm{mm}$, width $2.20 \mathrm{~mm}$ (length/width ratio 1.52). Elytra/pronotum width ratio 1.45 . (holotype).

Redescription. Body dark brown to blackish, legs dark reddish, antennae and tarsi orange-red, integument generally matt, partly glossier on the intervals and the keels.
Vestiture: setae scarce on the rostrum, short and transversely inserted into the punctures; setae on the pronotum slightly erect, transverse or oriented forwards; setae on the elytra long, narrow, erect, limited to the odd intervals and usually grouped on the low humps; scales scarce on the elytra, short and small, not raised, scattered on the whole surface. Rostrum nearly as long as the pronotum, regularly curved in lateral view except towards the base, where it is flattened together with the vertex; dorsum from base to antennal insertion matt, with three longitudinal irregular narrow glossy lines, converging basad and apicad, which delimitate rows of round punctures; apex beyond antennal insertion glossy, minutely punctulate. Sides with a row of punctures, pregenae glossy below the apical part of the scrobes, with small, regular punctures. Scrobes linear, deep, glossy. Scape of antennae regularly and distinctly thickened at apex, with some thick setae; segments 1 and 2 of funicle slightly longer than wide, segments 3-7 isodiametric; club ovate. Vertex broad, with punctures similar to those on the base of the rostrum, slightly more spaced and with flat intervals; sides above the eyes glossy, unpunctured. Eye triangular. Pronotum as long as broad; base truncate, apex slightly produced above the head, sides subparallel from the base to the 
51

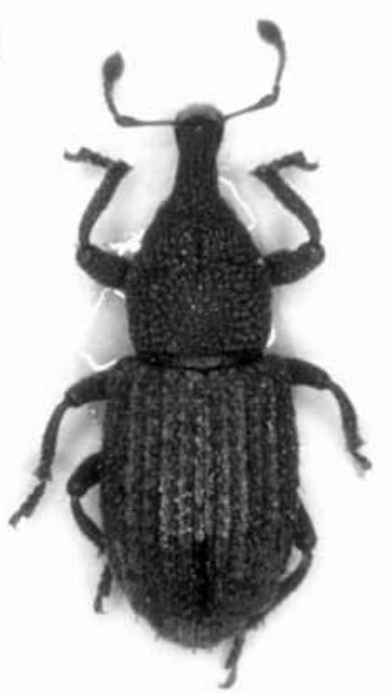

54

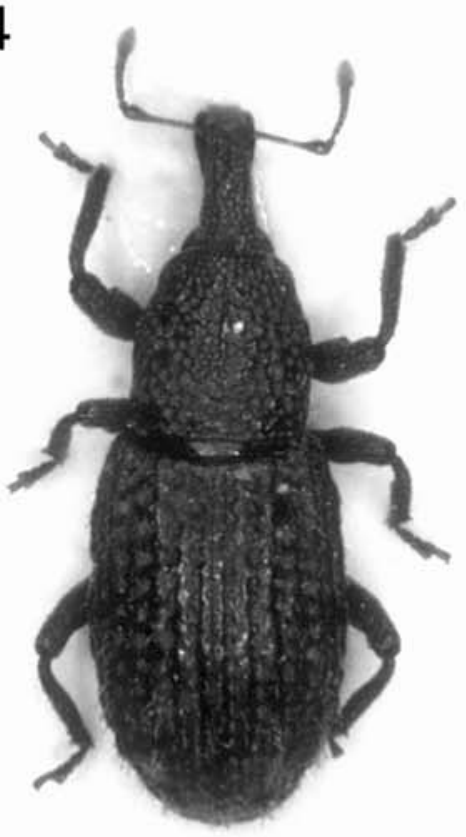

57

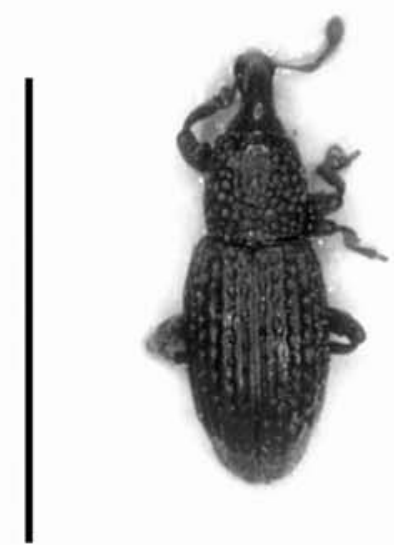

52

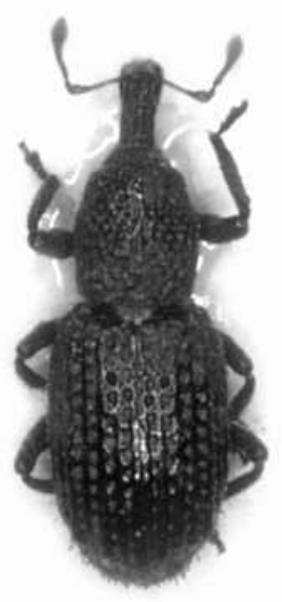

55

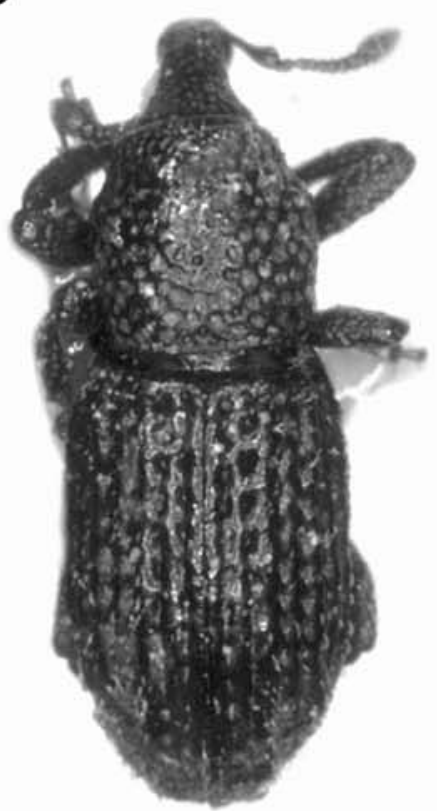

58

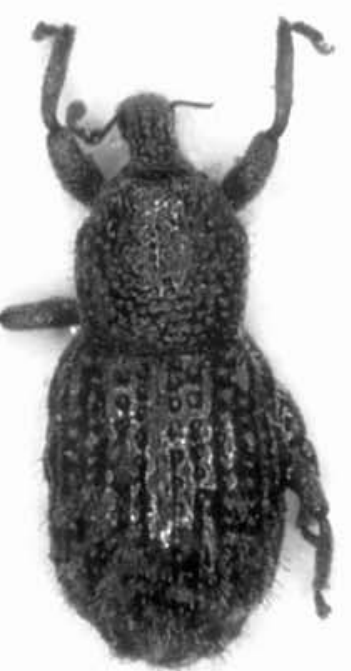

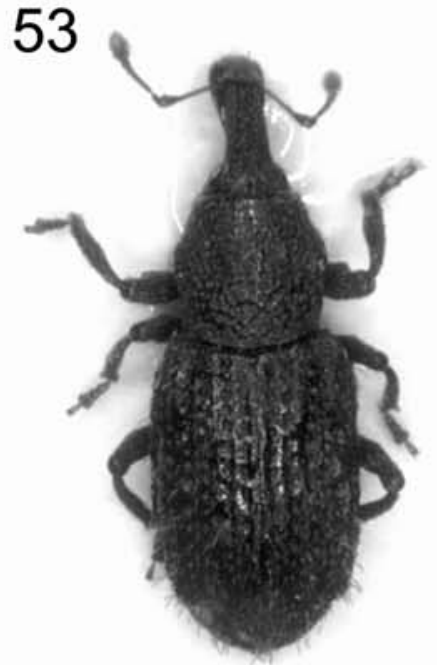

56

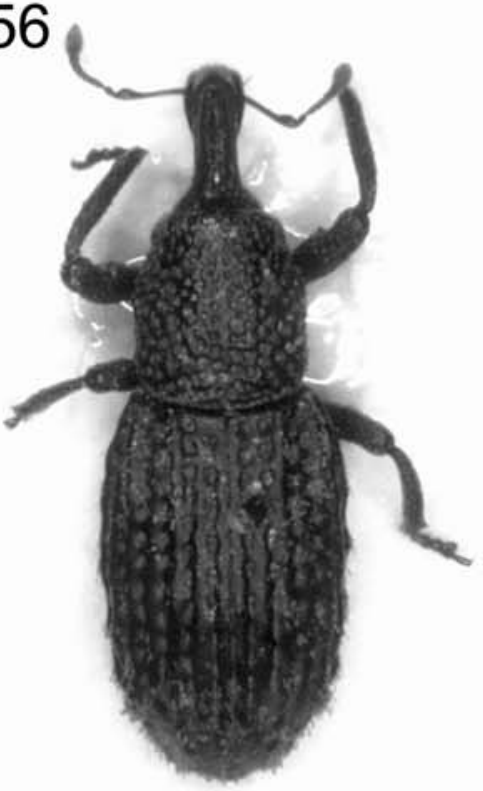

59

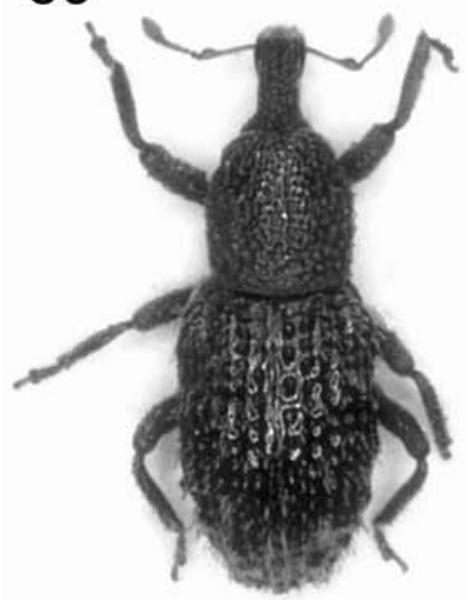

Figs 51-59. Body of: M. parbatensis, paratype (51); M. kaligandaki, holotype (52); M. setulosus, holotype (53); M. morimotoi, Deorali (54); M. minimus, holotype (55); M. maior, holotype (56); M. minor, holotype (57); M. shiva, holotype (58); M. laurae, paratype, Budubara (59). Bar: Figs 51-54, 56-59: 4 mm; Fig. 55: 2 mm. 
apical third, more convergent apicad. Surface moderately convex, with round dense punctures; intervals very narrow, sometimes reticulate; apical part with smaller punctures; median line very narrow, glossy, hardly differentiated and mainly visible in the apical half; sides with dense round punctures. Elytra about 1.5 times longer than broad, sides moderately curvilinear, with maximum width beyond their mid length; intervals narrower than the punctures of the striae, weakly convex, particularly the odd intervals, continuous for the whole length, intervals 3 and 5 with indications of oblong humps, of which only that at the apex of interval 5 is slightly more elevated. Femora moderately clavate, with a microscopic tooth at middle of the inner side; tibiae short, flattened; vestiture of the legs consisting of nearly aligned weakly recumbent setae; fringe of setae at apex of the fore tibia complete, long; segment 1 of the fore tarsi conical, segment 2 isodiametric, half as long as 1 ; segment 3 with lobes not developed; claws free, simple, lacking tooth. Ventrite 1 and 2 with round punctures, intervals as wide as the punctures; intervals 3 and 4 glossy, nearly unpunctured; interval 5 with shallower, irregularly set, not well delimited punctures. Genitalia: see Figs 3-4, 14, 34, 38.

Material examined. Holotype 0 : NEPAL: “277, Nepal, Taplejung Distr., Simbua Khola, Yalung, $3450 \mathrm{~m}$, Berlese,

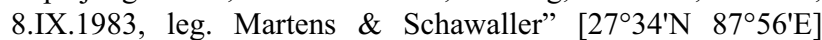
(SMNS). Paratype $\delta$ : same data (ZIN) [cited as $q$ by Zherikhin, 1987: 38]. Non-type material: NEPAL: "Nepal 361, Taplejung Distr., Upper Simbua Khola, near Tseram, m 3250-3350, 10-15.VII.1988, leg. W. Schawaller" [2732'N

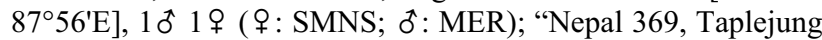
Distr., descent from Pass Deorali to Hellok, 2800-2600 m, mature mixed forest, 17.V.1988, Martens \& Schawaller legg." $\left[27^{\circ} 35^{\prime} \mathrm{N} 87^{\circ} 52^{\prime} \mathrm{E}\right], 10^{\star}$ (SMNS).

Variation. A certain polymorphism in the few known specimens has been observed in the shape of the pronotum, which can be slightly more elongated than in the holotype, with ratio length/width 1.10 . The elytral morphology and the setae distribution are quite uniform. The $\$$ from Tseram shows a microscopic thickening at the base of the claws.

Distribution. M. morimotoi is known from a few neighbouring localities in north-eastern Nepal (Fig. 79).

\section{Microplinthus minimus Zherikhin, 1987}

Figs 11-12, 18, 19, 41, 55, 64, 73

Microplinthus minimus Zherikhin, 1987: 40.

Measurements. Body length $2.88 \mathrm{~mm}$. Rostrum: length 0.84 $\mathrm{mm}$, width at base $0.34 \mathrm{~mm}$; width between antennae $0.26 \mathrm{~mm}$, width at apical plate $0.33 \mathrm{~mm}$. Pronotum: length $0.96 \mathrm{~mm}$, width $0.95 \mathrm{~mm}$ (length/width ratio 1.01). Elytra: length 1.80 $\mathrm{mm}$, width $1.19 \mathrm{~mm}$ (length/width ratio 1.51). Elytra/pronotum width ratio 1.25 (holotype).

Redescription. Body dark brown, matt; rostrum and legs reddish, glossier; antennae and tarsi light red-orange. Vestiture: setae on the rostrum nearly indistinct, very short and small; setae on the pronotum larger, sparse, appressed or slightly lifted and recumbent to integument; setae on the elytra very short, broad, recumbent, uniseriate on odd intervals, occasionally present also on even intervals, mainly on the declivity; scales only slightly shorter than the setae, sparse, more frequent on the declivity; setae on the legs narrow, short, appressed to integument. Rostrum short and thick, shorter than the pronotum; base very wide, as wide as the apical plate, dorsum distinctly converging towards the antennal insertion; regularly curved in lateral view from near the base to apex, not sinuate beyond vertex. Dorsum with coarse round punctures irregularly aligned; interspaces narrow, glossy, not keeled, irregular, particularly the barely distinct median line; apex glossy. Scrobes slightly broadened basad, upper and lower margins distinctly keeled. Scape of antennae short, robust, thickened at apical third; funicle shortened, segment 1 globose, 2 barely longer than wide, 3-7 progressively more transverse. Head short, vertex as strongly punctured as the base of the rostrum; eyes flat. Pronotum isodiametric, with truncate base, sides weakly and regularly curved, their maximum width at middle; slightly narrower at apex. Dorsum densely and coarsely punctured, interspaces narrow, slightly convex; median line not differentiated. Elytra oblong, at base as large as the base of the pronotum, very weakly broadened, scarcely broader than pronotum, with sides subparallel, regularly converging towards the apex, apex nearly straight between the intervals 3 of each elytron. Intervals linear, narrower than the punctures on the dorsum, wider on the declivity and lacking humps or granules; scarcely convex, 3 and 5 at their base slightly higher than the even intervals; punctures on the striae broader at the base, progressively narrowed and shallower towards the declivity; interspaces between the punctures very narrow, lacking granules. Femora punctured, tibiae with shallow longitudinal wrinkles; tarsi small, segment 3 larger than 2, claws simple. Ventrites 1 and 2 with sparse punctures, 3-4 smooth, 5 with small and dense punctures. Aedeagus: Figs 11-12, 18.

Material examined. Holotype $\delta$ : NEPAL: "Nepal, Kaski Distr., above Dhumpus, 2100 m, Berlese, 8-10.V.1980, Martens \& Ausobsky legg." [ $\left.28^{\circ} 15^{\prime} \mathrm{N} 83^{\circ} 54^{\prime} \mathrm{E}\right]$ (SMSN).

Distribution. M. minimus is known from a single locality in central Nepal (Fig. 79).

Remarks. This species is morphologically similar to $M$. laurae sp. n., particularly because of its size, habitus, puncturation of the pronotum and broad punctures of the elytra. It mainly differs from M. laurae by the short setae on the odd elytral intervals and the completely different aedeagus. See below for more remarks about its hypothetic phylogenetic relationships.

\section{Microplinthus maior (Zherikhin, 1987)}

Figs 22, 35, 46, 56, 65, 74

Leptanchonus maior Zherikhin, 1987: 20.

Microplinthus maior: Meregalli, 2003b: 324.

Figs 60-68. Pronotum of: M. parbatensis, paratype (60); M. kaligandaki, holotype (61); M. setulosus, holotype (62); M. morimotoi, Tseram (63); M. minimus, holotype (64); M. maior, holotype (65); M. minor, holotype (66); M. shiva, holotype (67); M. laurae, paratype, Budubara (68). Bar: Figs 60-63, 65, 67-68: 2 mm; Figs 64, 66: 1 mm. 

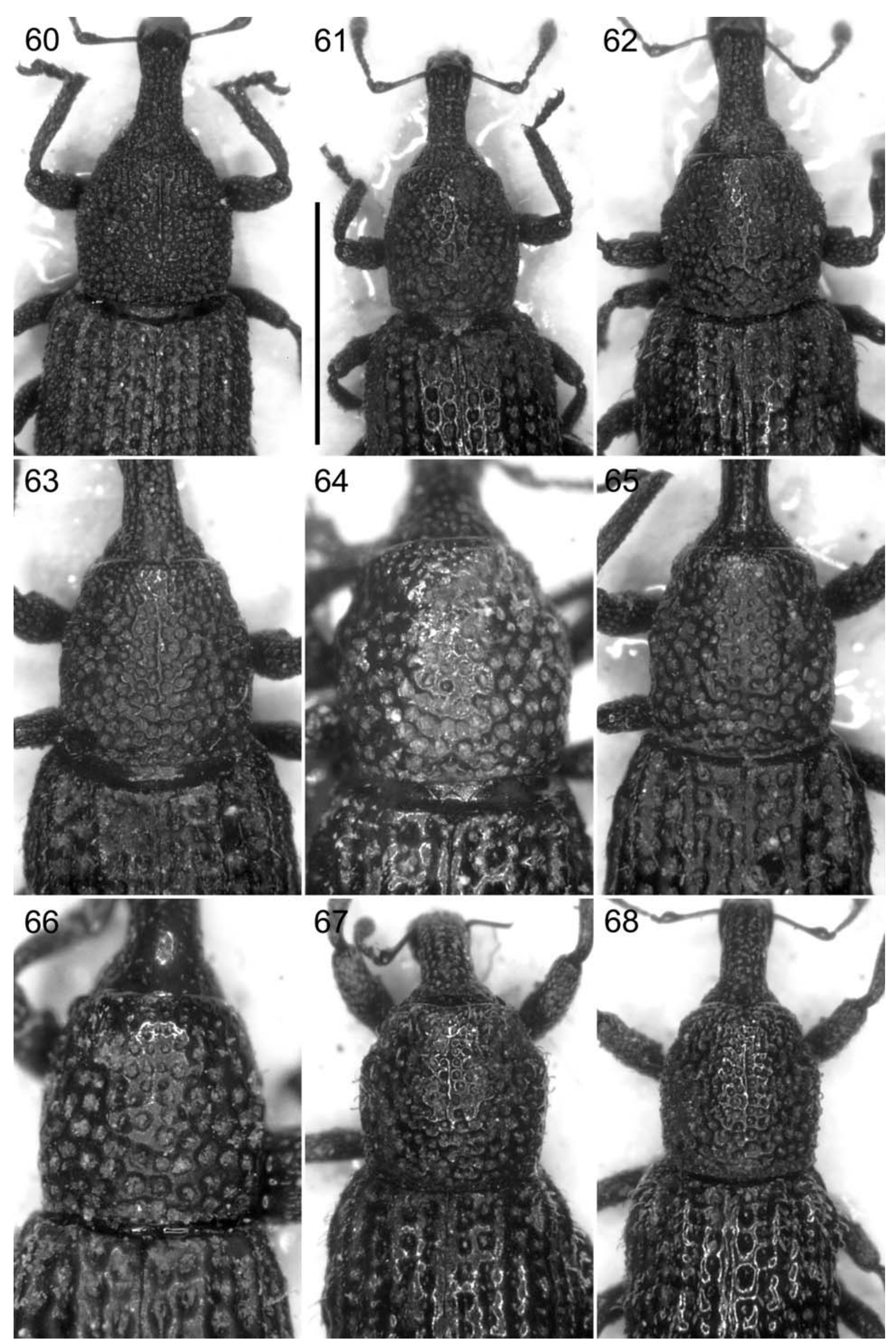
Zherikhin (1987) attributed this species, together with M. minor (Zherikhin, 1987) to Leptanchonus Morimoto, 1982, a genus erected for L. minatoi Morimoto, 1982 from Japan. Zherikhin, however, had no direct knowledge of the Japanese species, and based his interpretation of Leptanchonus solely on the description. The paratype of L. minatoi was examined in the course of the present study thanks to the courtesy of Prof. Morimoto. Although morphologically similar to the Himalayan taxa, it differs by several traits: rostrum broadened at base and linearly narrowing towards the apex, with sculpture almost extended to the apex, beyond insertion of the antennae, with glossy apical part very limited, hardly distinct; pregenae only expanded near the apex and very broad at this level, so that only the fore part of the scrobes, wide and deep, ovate, is visible from above; upper margin of the scrobes sharp, keel-like, sinuate, swollen outwards; lower margin of the scrobes short, reaching the underside of rostrum at its mid length; scape not sharply clavate, regularly thickened from its base; prementum very narrow; upper margin of the scrobes, from below, completely visible and nearly twice as wide as the base of the prementum; vertex distinctly narrower than the base of rostrum. Head very short, glossy, clearly separated from the rostrum, unpunctured, puncturation of the rostrum sharply interrupted at the insertion with head. Apex of the pronotum straight on dorsum and perfectly perpendicular at sides; post-ocular lobes missing; prosternum weakly emarginate, longer than the diameter of the fore coxae. Elytra with 9 striae, stria 10 very short, limited to base and immediately interrupted. Apex of the fore tibia with rounded, slightly oblique apical fringe of setae; segment 3 of tarsi with moderately developed lobes, underside with dense and long hair-like silvery setae. Tegmen with very short basal strut. Although the female genitalia of Leptanchonus have not been examined, the amount of differences of the two Himalayan species indicates that these cannot be included in the Japanese genus. Leptanchonus is to be excluded from Anchonini, but its inclusion in Aminyopini is doubtful.

Measurements. Body length $4.98 \mathrm{~mm}$. Rostrum: length 1.39 $\mathrm{mm}$, width at base $0.39 \mathrm{~mm}$; width between antennae $0.38 \mathrm{~mm}$, width at apical plate $0.51 \mathrm{~mm}$. Pronotum: length $1.61 \mathrm{~mm}$, width $1.51 \mathrm{~mm}$ (length/width ratio 1.06). Elytra: length 3.28 $\mathrm{mm}$, width $2.16 \mathrm{~mm}$ (length/width ratio 1.52). Elytra/pronotum width ratio 1.43 . (holotype).

Redescription. Body black, matt, integument microsculptured, legs dark brown, antennae and tarsi orange. Vestiture: dark yellow setae on the rostrum transversely inserted into the punctures, mainly on those of the row between the dorsal and the dorso-lateral keels; scarce setae on the pronotum longer, sub-appressed to the integument, scattered into the punctures; setae on the elytra limited to the odd intervals, mainly on the declivity, erect, sub-perpendicularly inserted, nearly as long as the intervals, slightly widened at apex and grouped on the humps; scales broad, rectangular, scattered and nearly appressed to the surface; setae on the legs short, relatively abundant, recumbent on the tibiae. Rostrum shorter than the pronotum, distinctly cylindrical, narrowed basally because of the vertical compression of the sides between the dorsal and the dorso-lateral keels; flattened dorsal part limited to the interspace between the dorsal longitudinal lines, with two rows of slightly spaced, shallow round punctures between the median and the dorsal lines; apex glossy; dorsum in lateral view mainly curved in the basal half, sinuate-concave between base and vertex, curvature nearly absent between middle of length and apex. Sides between the dorsal keels and the upper margin of the scrobes with three rows of regularly aligned small and shallow punctures; pregenae with elongate punctures, limited to the basal part and deepened in a small furrow. Upper margin of the scrobes not keeled, weakly sinuate; lower margin obtuse, scrobes deep and narrow. Vertex more than twice broader than the base of the rostrum, sparsely punctured, with wide interspaces between the punctures; eyes lateral, flat. Pronutum slightly longer than wide; base weakly arched, sides subparallel from the base to the apical third, where pronotum is slightly compressed and strongly converging apicad. Angle between the base and the sides rounded. Dorsum with narrow but distinct median line, punctures round, smaller near the median line, larger and more or less transversely aligned in the basal half; punctures on the sides sparse, isolate. Elytra almost $1.5 \times$ longer than broad, base as wide as that of the pronotum, sides shortly widened after humeri and very slightly rounded at the sides, maximum width at middle, regularly rounded at the apex. Intervals as wide as the striae; odd intervals slightly more convex than the even ones, 3 and 5 elevated at base and with low humps, hump at the apex of interval 5 slightly larger and more raised; interval 7 not elevated at base, with some low humps; even intervals nearly flat; striae with regularly impressed and spaced round punctures, interspaces between them flat, without granules, half as wide as the punctures. Femora punctured, not wrinkled, moderately thickened and with a small inner tooth; tibiae with longitudinal ridges; fringe of setae strongly ascending; tarsi short, segment 3 weakly lobed; claws simple. Ventrites 1 and 2 with dense punctures, interspaces nearly as wide as the punctures; ventrites 3 and 4 narrow, not distinctly punctured; punctures on ventrite 5 smaller and shallower. Sternite VIII: Fig. 35.

Material examined. Holotype $q$ : NEPAL: "NepalExpeditionen, Martens / 121, Ilam Distr., Gitang Khola, 2500 m, Lithocarpus, 28-31.III.1980, leg. Martens \& Ausobsky"

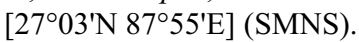

Distribution. The only known specimen was found in eastern Nepal (Fig. 79).

Figs 69-77. Rostrum of: M. parbatensis, paratype (69); M. kaligandaki, holotype (70); M. setulosus, holotype (71); M. morimotoi, Tseram (72); M. minimus, holotype (73); M. maior, holotype (74); M. minor, holotype (75); M. shiva, holotype (76); M. laurae, paratype, Budubara (77). Bar: $1 \mathrm{~mm}$. 

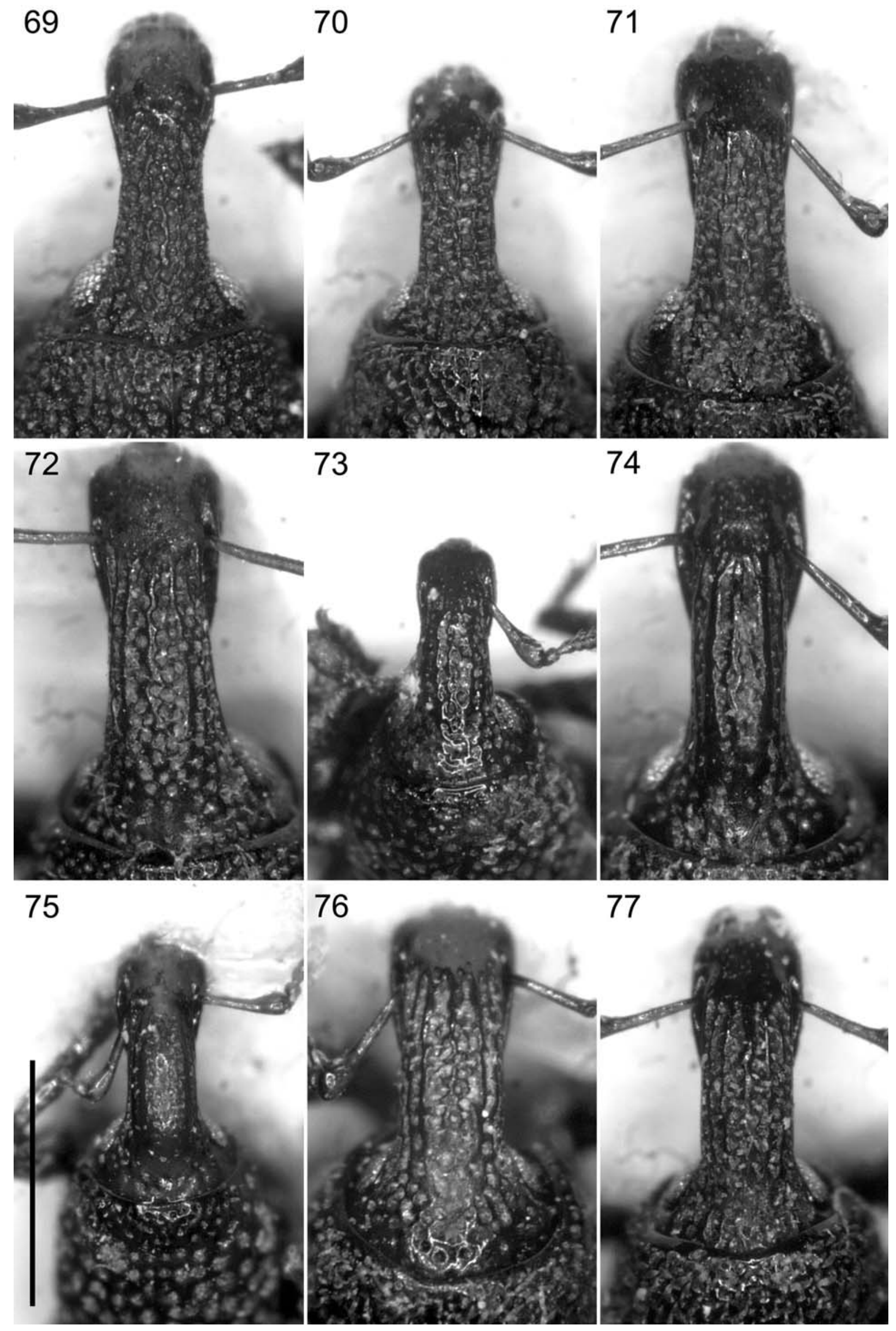
Remarks. The structure of the rostrum, very narrow at base, allows an easy differentiation from the other species of the genus. M. morimotoi is the species morphologically more similar, although probably not closely related phyletically, and is mainly distinguished by the rostrum distinctly broader at base, with dorsum narrowed from the base to the antennal insertion, regularly convex between the dorso-lateral margins.

\section{Microplinthus minor (Zherikhin, 1987)}

Figs 9-10, 17, 24, 42, 57, 66, 75

Leptanchonus minor Zherikhin, 1987: 22.

Microplinthus minor: Meregalli, 2003b: 324.

Measurements. Body length $3.02 \mathrm{~mm}$. Rostrum: length 0.91 $\mathrm{mm}$, width at base $0.29 \mathrm{~mm}$; width between antennae $0.26 \mathrm{~mm}$, width at apical plate $0.37 \mathrm{~mm}$. Pronotum: length $0.91 \mathrm{~mm}$, width $0.88 \mathrm{~mm}$ (length/width ratio 1.03). Elytra: length 2.01 $\mathrm{mm}$, width $\mathrm{mm} 1.24$ (length/width ratio 1.63). Elytra/pronotum width ratio 1.41 (holotype).

Redescription. Body red, of small size, integument matt; rostrum, legs and antennae lighter in colour. Vestiture very scarce: rare setae on the rostrum short and scarcely visible, inserted mainly on sides, directed upwards, appressed to integument; setae on the pronotum inserted into the punctures, as long as the punctures, usually nearly completely curved into the punctures; longer, erect setae on the elytra scattered and spaced on the odd intervals, not grouped in tufts, shorter than the interval width; short scales sparse, relatively frequent on the declivity, recumbent; setae on the legs short, recumbent. Rostrum as long as the pronotum, stout, curved, in lateral view conspicuously thickened in basal half; straight and slightly aciculate at apex, distinctly concave between base and vertex. Dorsum slightly convex between the barely visible dorsal keels, at base only slightly broader than between the antennae; median part with shallow, irregular punctures, lacking a clearly differentiated median line or keel; apex glossy, broadened, minutely punctured; punctures between dorsal and dorso-lateral lines deeper, well delimited by the broad dorso-lateral keels; sides above the scrobes with a deep furrow, delimited by the upper margin of the scrobe; pregenae with small punctures at the base. Scrobes parallel, narrow; upper and lower margins keeled. Antennae short, scape thickened at apex, with few broad setae; funicle shortened, segments 1 and 2 barely longer than wide, 3-7 transverse, club shortly oval. Head short, transverse, vertex smooth, with few punctures; eyes weakly convex. Pronotum subquadrate, sides nearly parallel from the base to the apical quarter, regularly and gently converging at apex; base nearly truncate, basal-lateral angle sharp; apex truncate, without trace of projecting lobe above head and with post-ocular lobes not developed; dorsum with regularly impressed round punctures, interspaces narrow but not linear, flat, distinctly microsculptured; median keel completely missing; punctures on the sides slightly deeper and more spaced, with slightly convex interspaces. Elytra oblong, not wider than pronotum at base; sides weakly and very uniformly curvilinear, with maximum width at the middle of their length and regularly converging at apex; intervals as broad or slightly broader than the striae, nearly but not completely flat, regular from base to apex, without any trace of humps; odd intervals as wide as the even intervals, 3 and 5 slightly more raised at base; striae narrow, with relatively shallow punctures, on stria 1 each puncture isolated from the others, punctures more densely impressed and wider on striae 4-6. Femora with a small triangular tooth, coarsely punctured; tibiae distinctly broadened apicad, wrinkled-punctured; tarsi short, segment 3 transverse; claws simple. Ventrites elongate, 3 and 4 only slightly narrower than $2 ; 1$ and 2 with spaced round punctures, 3-4 smooth, 5 with dense, smaller punctures partly confluent. Aedeagus: Figs 9-10, 17.

Material examined. Holotype $\delta$ : NEPAL: "NepalExpeditionen, Martens / 121, Ilam Distr., Gitang Khola, 2500 m, Lithocarpus, 28-31.III.1980, leg. Martens \& Ausobsky" [27 $\left.03^{\circ} \mathrm{N} 8^{\circ} 55^{\prime} \mathrm{E}\right]$ (SMNS). The holotype was cited by Zherikhin (1987: 22) as a + , but it is a $\delta$.

Distribution. The only known specimen was collected in eastern Nepal, sympatric and syntopic with M. maior (Fig. 79).

Remarks. This species is immediately recognized by the small size, the reddish integument, the rostrum thickened in the basal half in lateral view and with shallow punctures.

\section{Microplinthus shiva sp. $\mathbf{n}$.}

Figs 25, 44, 48, 58, 67, 76

Type locality. India, Darjeeling, Kalimpong, $27^{\circ} 04^{\prime} \mathrm{N}$ $88^{\circ} 29^{\prime} \mathrm{E}$.

Diagnosis. A Microplinthus of medium size (4.35 mm), with rostrum thick, feebly curved in lateral view; pronotum broad, transverse; elytra more convex, with relatively distinct oblong humps and abundant raised, long setae; legs with dense scale-like elliptical setae.

Measurements. Body length $4.35 \mathrm{~mm}$. Rostrum: length 1.22 $\mathrm{mm}$, width at base $0.43 \mathrm{~mm}$; width between antennae $0.41 \mathrm{~mm}$, width at apical plate $0.50 \mathrm{~mm}$. Pronotum: length $1.47 \mathrm{~mm}$, width $1.49 \mathrm{~mm}$ (length/width ratio 0.98). Elytra: length 2.95 $\mathrm{mm}$, width $2.01 \mathrm{~mm}$ (length/width ratio 1.47). Elytra/pronotum width ratio 1.37 (holotype).

Description. Body dark brownish-black, integument moderately glossy, antennae and tarsi reddish-brown. Vestiture: scarce setae on the rostrum short, transversely oriented, appressed to integument; setae on the pronotum longer, erect, usually curved or recumbent, mainly placed on the dorso-lateral margin, clearly visible from above, and on the anterior margin; setae on the elytra slender, scarcely broadened, erect, vertically inserted, relatively abundant on the low humps of the odd intervals, usually as long as the interval width; scales interspaced with the long setae and also scattered on the intervals, not completely appressed to integument, often recumbent. Rostrum short and thick; sides parallel, not converging to the antennal insertion, scarcely curved in lateral view, dorsum with 5 narrow, irregular longitudinal glossy lines, slightly converging apicad; dorsal keels more sharply delimited; median line very irregular, interrupted by punctures at the base and better delineate towards the 
apex; punctures between the keels irregular, rounded, interspaces very narrow, often raised; apex glossy, with dense punctures. Scrobes linear, glossy; antennal scape sharply thickened, nearly angular at apex, with broad apical setae; funicle with segment 2 longer than 1; segments 3-7 isodiametric; club oval. Vertex with punctures limited to the anterior part; eyes flat. Pronotum isodiametric, with base nearly truncate and sides rectilinearly widened from the base to the apical quarter, sharply converging apicad. Dorsum with regularly impressed dense round punctures; margins of the punctures, at least in part, distinctly convex; median line very small, barely visible in the anterior part; sides with dense punctures, partly fused in longitudinal rows whose lower margin is broadly raised. Elytra broadened, distinctly more convex towards $2 / 3$ of their length in lateral view; base slightly wider than the base of the pronotum, sides sharply widened from the base, subparallel up to the apical quarter and sharply converging at apex; intervals as wide as the striae; intervals 3, 5, 7 with an oblong obtuse hump at the base and irregularly convex for the whole length, intervals 3 and 7 with a higher hump on the declivity, interval 5 interrupted in an oblong hump at the beginning of the declivity; even intervals nearly flat; punctures of the striae oval, not deeply impressed, somewhat irregular, smaller and particularly shallow on the declivity, where they are barely visible. Legs robust, fore femur with a sharp minute tooth; middle and hind femora with nearly indistinct teeth; tibiae with deep rough sculpture, forming longitudinal wrinkles; tarsi stout and compact; claws simple, without visible inner tooth. Ventrites 1 and 2 with isolate round punctures, intervals nearly as wide as the punctures on the segment 2. Genitalia: the apex of the aedeagus was damaged during the dissection.

Type material. Holotype ô: "India, Darjeeling Distr., Umg.

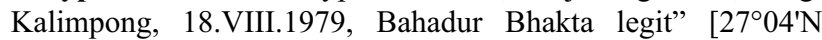
$\left.88^{\circ} 29^{\prime} \mathrm{E}\right]$ (NHMB).

Etymology. Shiva, a noun in apposition. Shiva, the Destroyer of Evil, is among the most praised and worshipped of all the gods in the Hindu religion. An auspicious festival, Shiva Ratri, is celebrated all over the world and is one of the most significant ceremonies held in Darjeeling.

Distribution. Only known from the single type collection, near the city of Kalimpong, in Eastern Darjeeling (Fig. 79).

Remarks. The new species differs from all the other Microplinthus by the slightly broader form, the rostrum short, nearly straight in lateral view, the elytra more convex, the intervals with low but clearly distinct oblong humps and the long, erect narrow setae on the intervals of the elytra.

\section{Microplinthus laurae sp. $\mathbf{n}$.}

Figs 7-8, 16, 20, 31-32, 43, 59, 68, 77

Type locality. India, Darjeeling, Lava, $27^{\circ} 05^{\prime} \mathrm{N} 88^{\circ} 41^{\prime} \mathrm{E}$.

Diagnosis. A Microplinthus of small to medium size $(3.8-4.2 \mathrm{~mm})$, mainly characterised by the vestiture composed of broad, slightly recumbent setae, the elytra slender, with their maximum width near the base, with wide punctures, the glossy integument and the very sharply thickened, nearly angular apex of the scape.

Measurements. Body length $3.95 \mathrm{~mm}$. Rostrum: length 1.01 $\mathrm{mm}$, width at base $0.34 \mathrm{~mm}$; width between antennae $0.32 \mathrm{~mm}$, width at apical plate $0.42 \mathrm{~mm}$. Pronotum: length $1.23 \mathrm{~mm}$, width $1.20 \mathrm{~mm}$ (length/width ratio 1.02). Elytra: length 2.51 $\mathrm{mm}$, width $1.61 \mathrm{~mm}$ (length/width ratio 1.56). Elytra/pronotum width ratio 1.34 (holotype).

Description. Body dark brown to blackish, moderately glossy, particularly on the elytra. Vestiture: scarse setae on rostrum short, transversely placed, recumbent against integument; setae on the pronotum broader, sub-erect, curved against integument, mainly oriented forwards; setae on the elytra long, erect, distinctly broadened towards the apical third, sparsely aligned in a single row on the intervals and grouped in places, mainly on the traces of low humps; scales recumbent, scattered along the intervals, not frequent. Rostrum shorter than the pronotum, regularly curved from the base, slightly sinuate before the vertex in lateral view; dorsum with 3-5 irregular longitudinal lines delimiting 3 rows of round, dense and regularly aligned punctures; apex glossy; pregenae glossy, with small punctures. Scape of antennae slender, thin at base and sharply and strongly, nearly angularly thickened at apex, where 1-2 broad setae are present. Head short, vertex as strongly punctured as the base of rostrum; eyes flat. Pronotum subquadrate, sides subparallel or weakly diverging up to the apical quarter, more sharply converging at apex. Dorsum with dense and deep round punctures, interspaces narrow, raised, median keel not differentiated; sides with sculpture similar to that on dorsum. Elytra slender, glossy, at base as wide as the base of pronotum, sides not or very weakly curvilinear, maximum width in the basal part, intervals much narrower than the punctures on the striae, weakly convex, with barely visible indications of low, scarcely differentiated oblong humps; punctures on the striae broad, dense, rounded and deeply impressed, regularly aligned. Femora short, with a small triangular inner tooth, surface with dense round punctures; tibiae slender, slightly widened from base to apex, apical fringe of setae ascending; tarsi short, compact, segment 2 transverse; claws simple, lacking inner teeth. Ventrites 1 and 2 matt, deeply microsculptured, with large round punctures; 3-4 nearly smooth, 5 with smaller and denser punctures; 3-5 glossier, less deeply sculptured. Aedeagus: Figs 7-8, 16.

Type material. Holotype $\widehat{\delta}$ : INDIA: "India, Darjeeling Distr., Lava, m 2035, 5.XI.1980, B. Bhakta legit" $\left[27^{\circ} 05^{\prime} \mathrm{N}\right.$ $\left.88^{\circ} 41^{\prime} \mathrm{E}\right]$ (NHMB). Paratypes: same data as the holotype, $10^{\star}$ (MER); "India, Darjeeling Distr., Alagara, m 1700, 1.XII.1980, B. Bhakta legit", $1 \delta^{\top}$ [27 $\left.07^{\circ} \mathrm{N} 88^{\circ} 35^{\prime} \mathrm{E}\right]$ (NHMB); "India, Darjeeling Distr., Budubara, 28.XI.1980, B. Bhakta legit" 1 ㅇ (NHMB); "Darjeeling, m 2150, 30.V.1975, W. Wittmer legit", $10^{\circ}\left[27^{\circ} 02^{\prime} \mathrm{N} 88^{\circ} 16^{\prime} \mathrm{E}\right]$ (NHMB). Dubious locality: "Nepal, Chandam Bari, m 3350, 26.VI.1979, Bhakta", 2 \% $\left[28^{\circ} 10^{\prime} \mathrm{N}\right.$ 852'ㄹ (1 9 NHMB, 1 ㅇ MER). Other material: E Sikkim, Khyonthang, m 1800, 25.IV.1985, C.J. Rai, 1 \% (NHMB).

Variation. The examined specimens are extremely uniform. Ventrite VIII of $q$ has arms joined above base (Fig. 31). The $\delta$ from the town of Darjeeling has slightly narrower setae; the 
specimen from East Sikkim, Khyonthang has sternite VIII with arms joined very near to the bifurcated base (Fig. 32), the pronotum with more regularly rounded sides and its maximum width at the middle, the elytra with narrower punctures and setae apparently narrower. Unfortunately this specimen is damaged, lacking the antennae, and has lost most of its vestiture, so that these differences cannot be correctly evaluated. It may be referred to a local population, although distinct morphology of the sternite VIII could be significant. The two specimens labelled Chandam Bari, in central Nepal, do not show any variation with respect to the specimens from Darjeeling, more than $200 \mathrm{~km}$ apart. It must be remarked that, as reported by Dr. Brancucci (NHMB, personal communication), some confusion occasionally occurred in the labelling of collections by Bhakta. Considering that all species of the genus are strictly localised, the data for Nepal are considered dubious.

Etymology. Named after my very close friend Laura Guglielmone, botanist. The choice of dedicating this, and not any other, species to her is intentional: M. laurae is in fact sympatric and syntopic with Falsanchonus roggeroi Meregalli, 2003, which was named in memory of Laura's husband.

Distribution. The species is known from Northern India, Darjeeling, and probably East Sikkim. See above for remarks on the two specimens apparently collected in central Nepal (Fig. 79).

Remarks. The new species differs from M. morimotoi by the smaller size, the elytra subparallel, with their maximum width before the middle of their length and the sides somewhat tapering towards the apex, the distinctly broader setae, the very wide punctures of the striae, the glossier integument, the rostrum more regularly curved in lateral view from the base, slightly concave before vertex. See treatment of $M$. minimus for differences from that species. M. laurae is sympatric with $M$. shiva sp. n., which differs by the larger size, the shorter and more convex elytra, the odd intervals with humps and the more slender setae grouped in tufts.

\section{PHYLOGENETIC RELATIONSHIPS}

Zherikhin (1987) erected the genus Microplinthus for three species from central and eastern Nepal but did not include it in any tribe-rank taxon in Molytinae, because of uncertainty in the boundaries of the various tribes. The author preferred to use the informal rank of "group", and attributed Microplinthus to the "Anchonidium-group", associating it, even though not formally, to the tribe Typoderina Voss, 1965 ("The name Typoderina Voss 1965 is available for this group of genera, but I do not use it here because the rank of the group is uncertain to me", Zherikhin, 1987: 37). The association of Microplinthus with Anchonidium Bedel, 1884 was determined by a combination of characters, such as the 7-jointed antennal funicle, the "normal eyes" (sic!), the non-carinate pronotum and elytra, and the "continuous" (sic!, = contiguous) fore coxae. Zherikhin (1987), however, indicated some differences with respect to Anchonidium, such as the narrow, almost parallel-sided elytra, the presence of post-ocular lobes on the pronotum, and the tibiae with strongly oblique apical fringe of setae and ascending corbel. Alonso Zarazaga \& Lyal (1999) referred Anchonidium to the tribe Typoderina, and listed Microplinthus in this tribe. Zherikhin (1987) did not examine the female genitalia, which offer good evidence to establishing phylogenetic affinities in the Molytinae. In particular, the sternum VIII of Microplinthus has a bifurcate base, a state usually seen in the tribe Aminyopini Voss, 1956. Most of the genera in this tribe, in combination with the bifid base of the sternum VIII, show a more or less developed inner tooth on the tarsal claws. This tooth is usually smaller, or even missing, in the taxa associated to leaf-litter, probably after secondary reduction, and in some cases, such as in the genus Falsanchonus Zherikhin 1987, the degree of development of the tooth, and even its presence, varies among the different species (Meregalli, 2003b). The three species of Microplinthus known to Zherikhin and the two originally described as Leptanchonus do not show any evidence of inner teeth on the claws, but M. parbatensis sp. n. presents a minute denticle. The inclusion of Microplinthus within the tribe Aminyopini is thus confirmed.

Within this tribe, the closest relationships are shared with Falsanchonus. The two genera share several character states, probably to be considered as synapomorphies, and they appear to be sister taxa: rostrum stout, curved, with several rows of punctures abruptly interrupted at the insertion of the antennae, apex glossy, smooth or minutely punctulate; head punctured, more or less inserted into the pronotum; vertex broad, much wider than the base of the rostrum; scape of the antennae thickened apicad and provided with some apical setae; identical structure of epistoma, oral opening and prementum; pronotum with dense round punctures and with a rudimental median line; disposition of the coxae and form of the sterna, as well as similar puncturation of the underside and general morphology of the genitalia. As previously observed (Meregalli, 2003b), the main apomorphy characterising Falsanchonus is the rostrum stout, curved at 60-90 ${ }^{\circ}$ with respect to the head, strongly thickened basad and aciculate apicad in lateral view; other differentiating traits of this genus are: anterior margin of the pronotum with usually more developed post-ocular lobes and a produced dorsal lobe above the head; stria 10 incomplete, only present at the base of the elytra; different form of the fringe of setae at the apex of fore tibia; claws with the inner tooth usually present, although often microscopic. Microplinthus can be distinguished from the other genera of Aminyopini known so far by the small size (2.8-5 $\mathrm{mm})$, the rostrum curved, moderately thickened in lateral view, not beak-shaped as in Falsanchonus, glossy on dorsum, abruptly smoothed beyond the insertion of antennae, the elytra with only indications of oblong humps, with a vestiture composed of narrow or broad, recumbent or, more often, long and erect, setae and triangular to elongate scales, the scarcely sclerotised aedeagus with rounded or subacute apex; the sternite VIII of the female with bifurcate base and arms joined at basal quarter or separate for their entire length, converging basad.

The inclusion of M. parbatensis in Microplinthus may be questionable. Its peculiar traits, often apparently intermediate with the monotypic genus Microniphades 
TABLE 1. Matrix of character states. N. d. = not determined.

\begin{tabular}{crrrrrrrrrrr}
\hline Character & N. var. & M. sch. & M. par. & M. kal. & M. set. & M. mor. & M. min. & M. laur. & M. shiva & M. maior & M. minor \\
\hline 1 & 1 & 2 & 3 & 3 & 3 & 2 & 4 & 3 & 3 & 2 & 4 \\
2 & 1 & 2 & 2 & 2 & 2 & 3 & 2 & 3 & 3 & 3 & 4 \\
3 & 1 & 1 & 1 & 1 & 2 & 2 & 2 & 2 & 2 & 3 & 3 \\
4 & 1 & 1 & 1 & 1 & 1 & 1 & 1 & 1 & 1 & 2 & 2 \\
5 & 2 & 1 & 1 & 1 & 2 & 2 & 2 & 3 & 3 & 3 & 3 \\
6 & 1 & 2 & 2 & 2 & 3 & 3 & 3 & 4 & 4 & 3 & 3 \\
7 & 1 & 1 & 1 & 1 & 3 & 2 & 3 & 3 & 3 & 2 & 2 \\
8 & 1 & 1 & 1 & 3 & 2 & 2 & 3 & 3 & 3 & 1 & 3 \\
9 & 1 & 2 & 2 & 2 & 2 & 2 & 2 & 2 & 2 & 2 & 2 \\
10 & 2 & 2 & 1 & 2 & 1 & 1 & 2 & 3 & 3 & 1 & 1 \\
11 & 2 & 2 & 2 & 2 & 2 & 2 & 2 & 3 & 3 & 1 & 1 \\
12 & 2 & 1 & 1 & 1 & 2 & 1 & 2 & 1 & 1 & 2 & 2 \\
13 & 1 & 2 & 2 & 3 & 3 & 3 & 3 & 3 & 3 & 3 & 3 \\
14 & 1 & 2 & 2 & 3 & 3 & 4 & 4 & 4 & 4 & 4 & 4 \\
15 & 1 & 2 & 2 & 3 & 3 & 3 & 5 & 4 & 3 & 6 & 6 \\
16 & 1 & 1 & 1 & 1 & 1 & 3 & 2 & 2 & 3 & 3 & 2 \\
17 & 1 & 2 & 2 & 2 & 2 & 4 & 3 & 3 & 4 & 4 & 3 \\
18 & 1 & 2 & 2 & 2 & 2 & 2 & 2 & 2 & 2 & 2 \\
19 & 1 & n.d & n.d. & 1 & n.d. & 1 & 2 & 1 & 1 & n.d. \\
20 & 1 & 5 & 2 & n.d. & 3 & 3 & n.d. & 4 & n.d. & 4 & n.d. \\
21 & 1 & 1 & 1 & 3 & 2 & $2-3$ & 3 & 3 & 3 & 3 \\
\hline
\end{tabular}

N. var. = Niphades variegatus, M. sch. = Microniphades schawalleri, M. par. = Microplinthus parbatensis, M. kal. $=$ M. kaligandaki, M. set. $=$ M. setulosus, . mor = M. morimotoi, M. min. $=$ M. minimus, M. laur. $=$ M. laurae.

Zherikhin, 1987, erected for M. schawalleri Zherikhin, 1987, and possibly plesiomorphic with respect to the other taxa specialized to leaf litter, could suggest that this species is basal not only to the other species of Microplinthus but to both Microplinthus and Falsanchonus: a paraphyletic classification would thus result. However, synapomorphies characterising Falsanchonus are so peculiar that it seems acceptable, at least at the present level of knowledge, to maintain the two genera distinct. Possible paraphylesis is a minor problem in the weevil subfamily Molytinae, which includes polyphyletic tribes, and may even be polyphyletic itself (Marvaldi et al., 2002). Alternatively, M. parbatensis could be attributed to a new genus, but this approach would eventually result, once that all taxa of Himalayan Molytinae are studied, in an excessive and not justified proliferation of monotypic or too small genera. Another classification of this species could be to include it in the genus Microniphades, but this interpretation would result in underevaluating the apomorphic character states typical of Microplinthus and

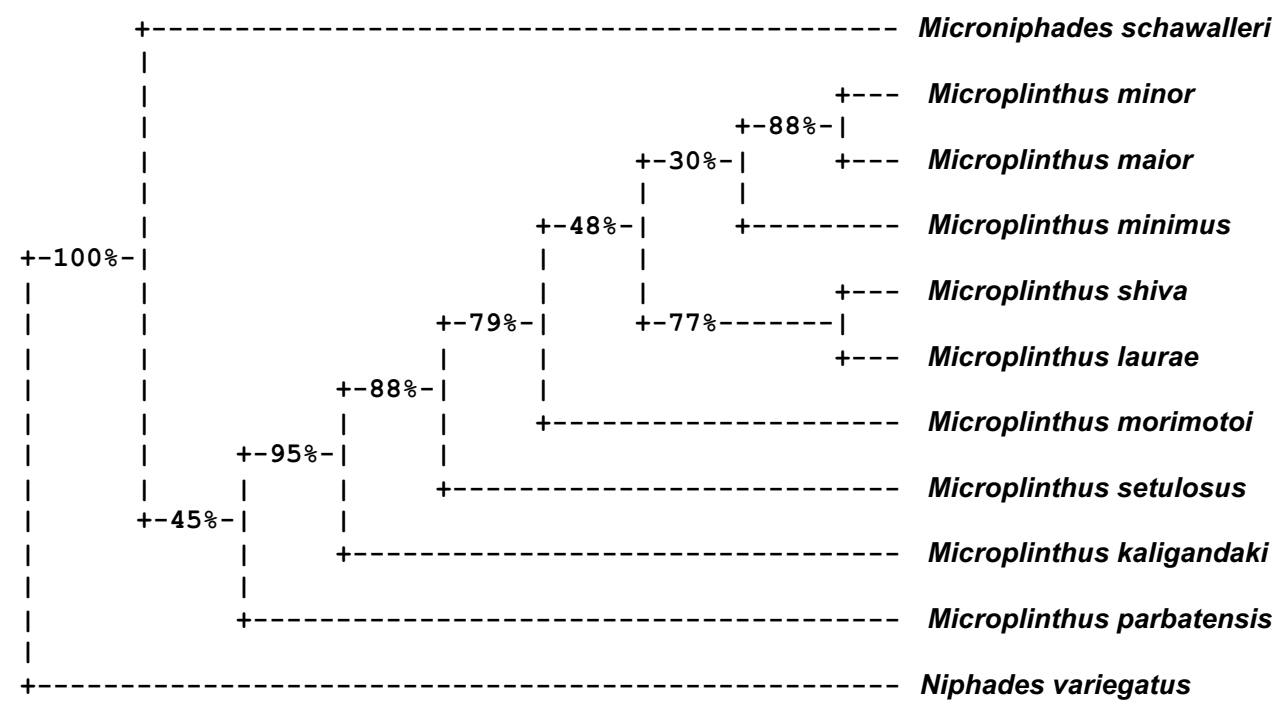

Fig. 78. Majority-rule consensus tree based on data obtained with the "Penny" parsimony analysis. Percentages indicate the number of times the group consisting of the species which are to the right of that fork occurred among the trees. 


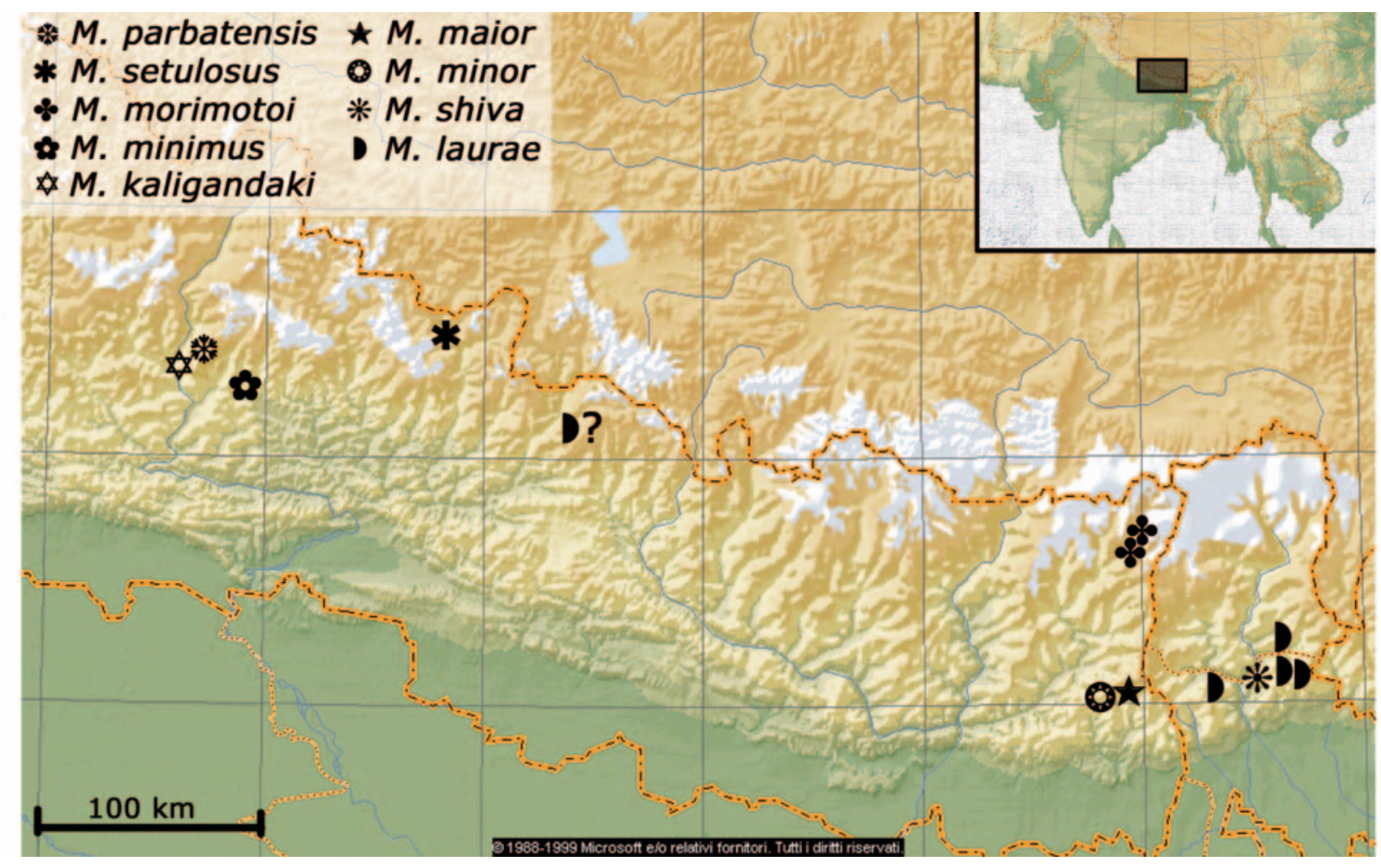

Fig. 79. Distribution map [map from Encarta World Atlas 2000 (Microsoft Corporation), elaborated with Photoshop 7.0 (Adobe Systems Incorporated)].

already present in $M$. parbatensis. Under a different approach, Microplinthus and Falsanchonus could be considered as convex groups (cf. Estabrook, 1978; 1986), and thus maintained as distinct genera, regardless to the classification of $M$. parbatensis.

The inference of mutual relationships among the species of Microplinthus is particularly complex. Six out of nine species are known in the holotype only, and few specimens are available for the other three, so that neither a complete analysis of genitalia of the two sexes, nor a precise definition of the states of "quantitative" traits, such as density of puncturation or deepness of sculpture, is possible. Moreover, the nearly $300 \mathrm{~km}$ wide gap between central and eastern Nepal, where no taxon of this genus has been reported from, and the fact that nearly all species are known from a single collection site, suggest that other species, which would add useful information, are still unknown. It should be added that the response to selective pressures in these isolated taxa, subject to similar environmental demands, may favour the independent fixation of homoplasic autapomorphies. A preliminary attempt to a reconstruction of phylogenetic relationships, performed with several parsimony methods included in the Phylogeny Inference Package PHYLIP 3.6 (Felsenstein, 2004) and using two species of Molytinae Aminyopini as outgroups (the winged Niphades variegatus (Roelofs, 1875) and Microniphades schawalleri) was carried out; it should be stressed that incompleteness of information regarding the phylogeny and biogeography of the whole tribe and consequent uncertainty in the choice of the outgroups and in determining the polarisation of the character states limit seriously the confidence of the results. However, this analysis allowed to obtain an overview of the hypothetical mutual relationships among the species; the majority-rule consensus phenogram generated by the largely used programs (Fig. 78) was the starting point for critical remarks, which took into account also alternatives suggested by a (subjective) interpretation of the apparently "more significant" traits and biogeographical considerations.

The following characters were considered informative (Table 1); state 1 was considered ancestral only when indicated, whereas the states in the other traits were not polarized; traits were not weighted.

1. Body size. Adaptation to leaf litter is often accompanied by smaller size, which is also an adaptation to high altitude. States: 1 , body size $>5 \mathrm{~mm} ; 2$, body size $=5$ $\mathrm{mm} ; 3$, body size $=4-4.5 \mathrm{~mm} ; 4$, body size $=3 \mathrm{~mm}$.

2. Rostrum, lateral view. Rostrum in these species can be more or less thickened basad; in all the other genera of the tribe, excluding Falsanchonus, the rostrum does not show any basal thickness, hence this state is considered apomorphic. States: 1, very scarcely curved and not thickened; 2, regularly curved, not thickened (Figs 39-41); 3: barely thickened (Figs 43-47); 4: distinctly thickened basad (Fig. 42).

3. Rostrum, puncturation. States: 1, small and dense punctures; 2, dense with visible longitudinal interspaces; 3: spaced, shallow.

4. Rostrum, base. A laterally compressed base of the rostrum is seldom found in Aminyopini and is considered the apomorphic state in Microplinthus. States: 1, not com- 
pressed, sides converging apicad; 2, compressed, sides not converging apicad.

5. Curvature of the rostrum in lateral view. States: 1, curvature continuous from the vertex to the apex; 2 , base of the rostrum flattened before the vertex; 3 , base of the rostrum slightly concave before the vertex.

6 . Scape. In some of these species the apex of the scape is peculiarly thickened; the scape angulate at the apex is considered the apomorphic state. States: 1, scape regularly thickened from the half of its length; 2, scape moderately thickened towards the apex; 3, apex thickened; 4, apex strongly thickened, nearly angulate (Figs 20, 25).

7. Setae at the apex of the scape. In all the Molytinae the setae at the apex of the scape are narrow and thin, hence the presence of broad setae is considered the apomorphic state. States: 1, setae narrow, hair-like; 2, setae moderately thickened; 3 , setae broad, often recumbent.

8. Funicle. States: 1, regularly developed; 2, moderately shortened; 3, very short, with segments 3-7 transverse.

9. Pronotum, sculpture of dorsum. States: 1, rough, without distinct punctures, with large tubercles and trace of broad median furrow; 2, smoother, with distinct punctures, lacking tubercles and with trace of median keel.

10. Pronotum, post-ocular lobes. States: 1, not developed; 2, present, scarcely developed; 3, present, well developed.

11. Pronotum, frontal lobe. Development of the frontal lobe may be related to adaptation to forest litter habitat, and is considered the apomorphic state. States: 1, not developed; 2, present, scarcely developed; 3, present, well developed.

12. Pronotum, apex. States: 1, emarginate at the middle; 2 , truncate.

13. Elytra, base. The loss of the humeri is directly correlated to winglessness, and is also subsequent to adaptation to the leaf litter habitat. States: 1, humeri regularly developed; 2 , weak trace of humeri; 3 , humeri completely missing.

14. Elytra, intervals and interspaces of the punctures. States: 1 , intervals with large glossy granules; 2 , intervals and interspaces of the punctures with small glossy granules; 3 , interspaces of the punctures with few low granules; 4, both intervals and interspaces of the punctures without granules.

15. Elytra, setae. Setae on the elytra have several different forms; apparently, broader and more recumbent setae are associated to higher adaptation to the forest litter environment. States: 1, short, hair-like, obliquely inserted; 2, short, rectangular, semi-erect; 3, longer than the intervals, nearly perpendicularly erect; 4 , broadened towards the apex; 5, broad, shorter than the intervals, curved, recumbent against integument; 6 , broad, shorter than the intervals, sub-erect, only slightly curved at the apex.

16. Elytra, setae. Distribution on the elytra. States: 1, quite regularly spaced; 2 , grouped; 3 , in tufts on the humps.
17. Elytra, humps on the odd intervals. The development of humps on the intervals seems to be the apomorphic state. States: 1, odd intervals with oblong glossy punctured granules; 2, intervals flat or weakly convex, without humps; 3, odd intervals with low, scarcely distinct humps; 4, odd intervals with humps.

18. Metathoracic wings. Winglessness is the apomorphic state. States: 1, wings present; 2 , wings absent.

19. Aedeagus. States: 1, median lobe curved; 1, median lobe flattened; 2, median lobe flattened, apex curved downwards.

20. Sternum VIII of female. States: 1 , arms joined for a long tract above the base; 2 , arms separate nearly up to the base (Fig. 30, 33); 3, arms approached towards the base (Figs 32, 34); 4, arms joined for a small tract above the base (Figs 31, 35); 5, arms X-shaped.

21. Claws, inner tooth. As discussed above, reduction or loss of the tooth is the apomorphic state in this genus. States: 1, inner tooth present (Fig. 37); 2, inner tooth missing, but an inconspicuous thickness present; 3 , no evidence of tooth.

The 1000 bootstrapped data sets obtained with the "Seqboot" program of the PHYLIP Package 3.6b (Felsenstein, 2004) were analyzed with the "Penny" program, with Wagner parsimony method, and resulted in 3885 most parsimonious trees; the majority-rule consensus tree is reported in Fig. 78. Majority-rule consensus trees obtained after analysis of the same data sets with other parsimony programs ("Mix", "Pars", etc.) often showed the same clusters, but differed in the proportion of the resulting groups.

Two major groups were recognised, one mainly distributed in central Nepal, the second present in Eastern Nepal and northern India. M. parbatensis, not surprisingly, was completely isolated with respect to the other species. It is evidently basal to all the other taxa, as indicated by the very significant state of the appendiculate claws. $M$. kaligandaki seems to connect $M$. parbatensis with the other taxa; this is suggested by the short and very regularly curved rostrum, the smooth intervals, the small but distinct granules between the punctures of the striae, the regularly spaced setae on the elytra, etc. However, $M$. kaligandaki might also be regarded as a sister taxon to $M$. setulosus, which also fell within this group; its main characters are the long setae, erect, regularly distributed on the intervals, which are flat and lack any trace of humps; the pronotum has a peculiar form, possibly an autapomorphic state, but it is very densely punctured, with a well delimited median line; its sculpture resembles that of the pronotum of $M$. parbatensis and is quite different from the other species. At the very base of the claws, at very high enlargement, it is possible to perceive a minute thickness, which could represent a remnant of the inner tooth. All the other species clustered in another group, apparently more derived and sustained by a high proportion in the majority-rule consensus tree $(88 \%)$, with $M$. morimotoi possibly basal to all the other taxa; at this regard it must be observed that one specimen of $M$. morimotoi shows a trace of basal thickness on the claws, not 
evidenced by the other specimens examined: retained polymorphism for this state could confirm a relatively lower derivation for this taxon with respect to the remaining species. Alternatively, M. morimotoi could be grouped with $M$. shiva (morphologically linked by the raised setae and humps on the elytra) or with $M$. maior (main shared traits are size and body aspect). The position of $M$. minimus is particularly uncertain and was not resolved by the majority-rule consensus tree with a significant confidence: in $30 \%$ of the trees obtained with the "Penny" program it was associated to the group M. maior - M. minor, whereas in $22 \%$ it fell within the clade $M$. shiva - M. laurae, basal to the two species. However, an alternative hypothesis, well justified biogeographically, would be to group it together with the other species from central Nepal. Morphologically, this would be suggested by the rostrum scarcely thickened, regularly curved in profile; this is an apparently plesiomorphic state which is lost in the species from eastern Nepal. Although superficially similar to $M$. laurae, this species is indeed quite peculiar, with an aedeagus different from that of all the other Microplinthus whose male genitalia are known; the unavailability of female specimens does not allow to take into account the important trait of sternum VIII. The distinct aedeagus morphology, the still retained plesiomorphic aspect of the rostrum and the distribution in central Nepal may suggest that this species represents an independent phylogenetic lineage, not closely related to those diffused in eastern Nepal. The states shared with these last species may be considered as autapomorphic homoplasies determined by the adaptation to the leaf-litter habitat. The four remaining species clustered in two different groups, each occurring in a large percentage of the trees. One group includes $M$. maior and M. minor, the second $M$. shiva and M. laurae. The former group is justified by the very peculiar form of the rostrum, which is compressed at its base, a feature unique in the genus, and has shallow and spaced punctures. Also the pronotum, which is truncate at the apex and with very small or no post-ocular lobes, and the appearance of the elytra, with narrow, regular, weakly convex intervals, short setae and small punctures on the striae, suggest that the two taxa may be closely related, regardless to their different size and colour of integument. They are sympatric in eastern Nepal. M. laurae and M. shiva, from Darjeeling and Sikkim, share the very significant state of the highly thickened, nearly angular apex of the scape, a state unique in the whole tribe. They also share the wide punctures on the striae, broader than the intervals. The former differs by the large setae and the smaller size, whereas $M$. shiva has higher humps on the elytra, pronotum more broadened and narrower setae arranged in tufts on the humps.

\section{BIOGEOGRAPHY}

Microplinthus seems endemic to the southern slopes of Himalaya, between central Nepal and northern India, with a centre of dispersal in central Nepal and another centre of dispersal in eastern Nepal and northern India (fig. 79). The easternmost limits of distribution cannot be stated because of the limited knowledge on the soil fauna of Bhutan, Assam, northern Myanmar and western China. Most species are only known from a single, or very few, collection sites; nevertheless, it seems evident that each species is strictly localised. Based on the phylogenetic analysis, the most primitive species should be those present in central Nepal, whereas apparently most derived taxa colonised eastern Nepal and northern India. This would imply that the colonisation routes for this genus proceeded towards the East, adapting to the forest litter habitat along the hills and mountains of the southern slopes of Himalaya.

The tribe Aminyopini has an Indo-African distribution (cf. Meregalli, 2003b for a list of the genera) and is composed by a winged genus, Niphades Pascoe, 1871, present in Africa and the Oriental Region, and several usually wingless genera. Three of these are native to tropical Africa, the others are diffused in the Oriental Region. Mutual relationships among African and Asian genera have not yet been investigated, however it seems likely that many of the Asian genera form a monophyletic unit, with particular regard to those linked to leaf litter. The southern slopes of the Himalayan chain host a large number of Aminyopini linked to leaf litter: other than Microplinthus, this represents the major centre of dispersal of the genus Falsanchonus (Meregalli, 2003b), and is colonised by several other still undescribed taxa of the tribe. Many other Molytinae linked to the soil are present in this area: 8 genera with 23 species are known so far (Zherikhin, 1987; Meregalli, 2003b), but many new taxa are presently under study (Meregalli, personal observation).

As noted elsewhere (Meregalli, 2003b) the richness of taxa associated to leaf litter in this area was probably favoured by a relative palaeoecological stability. In particular, although the sub-tropical or temperate broadleaved forests, specific habitat of these taxa, underwent several fluctuations since late Tertiary, they persisted in the southern slopes of Himalaya even during the late glacial maximum, probably not diffused in a continuous bend but rather scattered in patches delimited by drier, sub-steppic habitats (Ray \& Adams, 2001). This relative ecological stability should have permitted the conservation of a large amount of the ancient fauna which may have differentiated during the warmer and more humid Miocenic age, whereas the fragmentation of the habitats suitable to the soil fauna may have allowed vicariance events.

\section{LIFE HISTORY}

Very few data are available. The specimens collected by Martens and Schawaller were found sifting below Rhododendron shrubs and in mixed Lithocarpus forest; M. kaligandaki was collected in litter of oak forest. As often is the case with the soil-dweller weevils, these taxa do not seem to be specifically correlated to peculiar species of trees or shrubs, but rather to shady and humid habitats in broadleaved forest with abundant litter and relatively constant microclimatic conditions. 
ACKNOWLEDGEMENTS. I wish to thank friends and colleagues who helped with loan of specimens and various information: R. Anderson (CMNC), M. Barclay and C. Lyal (BMNH), M. Brancucci (NHMB), B. Korotyaev (ZIN), W. Schawaller (SMNS). I am indebted to my friend G. Osella for the critical reading of the manuscript and to J. Gómez-Zurita for some suggestions about the phylogenetic analysis.

\section{REFERENCES}

Alonso-Zarazaga M.A. \& Lyal C.H.C. 1999: A World Catalogue of Families and Genera of Curculionoidea (Insecta: Coleoptera) (Excepting Scolytidae and Platypodidae). Entomopraxis, Barcelona, $315 \mathrm{pp}$.

Aslam N.A. 1963: On the genera of Indo-Pakistan Cleoninae and Hylobiinae (Coleoptera: Curculionidae). Bull. Br. Mus. Nat. Hist. (Entomology) 13(3): 47-66.

EstaвrooK G.F. 1978: Some concepts for the estimation of evolutionary relationships in systematic botany. Syst. Bot. 3: $146-158$.

EsTABROOK G.F. 1986: Evolutionary classification using convex phenetics. Syst. Zool. 35: 560-570.

FelsensteIn J. 2004: PHYLIP (Phylogeny Inference Package) version 3.6b. Distributed by the author. Department of Genome Sciences, University of Washington, Seattle.
Marvaldi A.E., Sequeira A.S., O’Brien C.W. \& Farrell B.D. 2002: Molecular and Morphological Phylogenetics of Weevils (Coleoptera, Curculionoidea): Do Niche Shifts Accompany Diversification? Syst. Biol. 51: 761-785.

Meregalli M. 2003a: Stenanchonus Voss 1937, a junior synonym of Euthycus Pascoe 1885 (Insecta, Coleoptera, Curculionidae, Molytinae). Senckenberg. Biol. 82(1/2): 127-133.

Meregalli M. 2003b: The genus Falsanchonus Zherichin, 1987, with description of six new species (Insecta: Coleoptera: Curculionidae: Molytinae). In Hartmann M. \& Baumbach H. (eds): Biodiversität und Naturausstattung im Himalaya / Biodiversity and Natural Heritage of the Himalaya. Verein der Freunde und Förderer des Naturkundesmuseum Erfurt, pp. 323-335.

Ray N. \& Adams J.M. 2001: A GIS-based Vegetation Map of the World at the Last Glacial Maximum (25,000-15,000 BP). Internet Archaeology, 11 (http://intarch.ac.uk/journal/issue11/ rayadams_toc.html)

VAN DEN BERG M.C. 1972: The morphology of Eremnus cerealis Marshall (Coleoptera: Curculionidae). Ann. Univ. Stellenbosch (A) 47(1): 1-58.

ZHERIKHIN V.V. 1987: Curculionidae from the Nepal Himalayas. Part I. Molytinae (Insecta: Coleoptera). Stuttg. Beitr. Naturk. (A) 411: 1-43.

Received January 14, 2004; revised April 7, 2004; accepted August 11, 2004 